مجلة جامعة الملك عبدالعزيز: الآداب والعلوم الانسانية، م29ع3 ص ص: 165- 194 (2021م)

DOI:10.4197/Art.29-3.6

\title{
ثقافة العمل التطوعي لدى طالبات الجامعة في ضوء بعض المتغيرات الديموجرافية
}

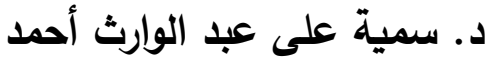

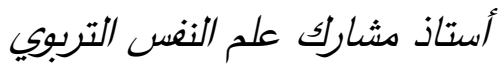

جامعة جدة - جدة - قسم علم النفس-كلية العلوم الاجتماعية -الدملكة العربية السعودية العباكية

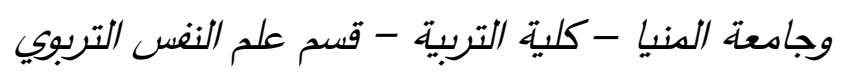

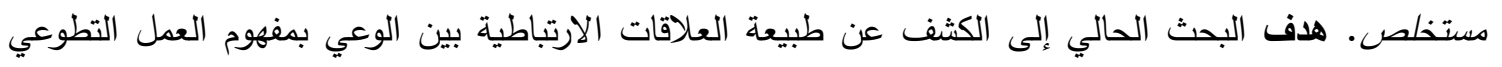

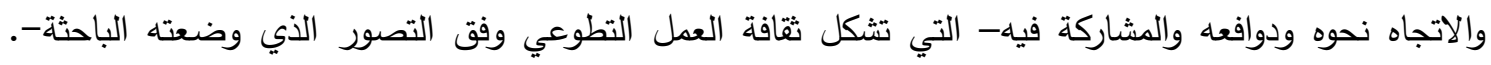

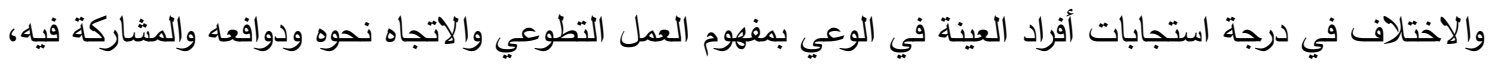

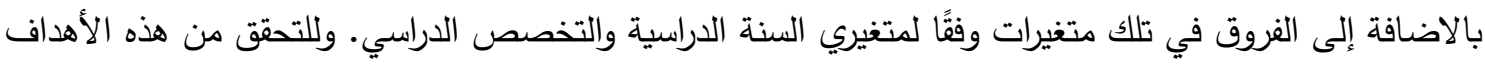

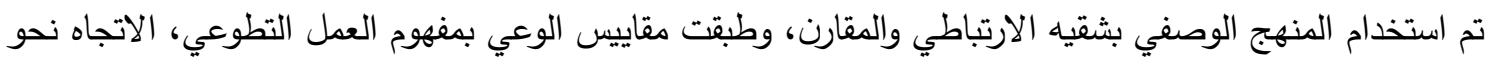

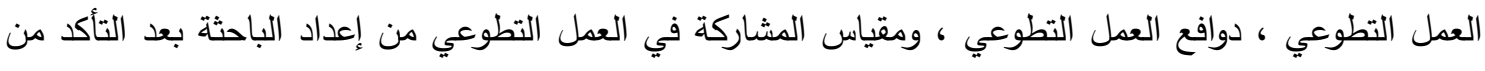

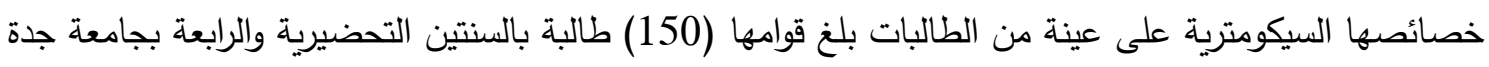

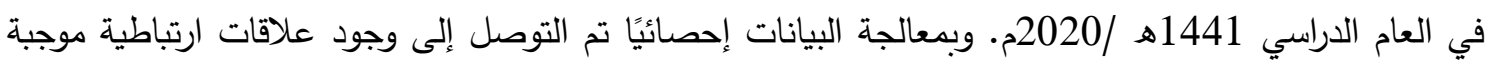

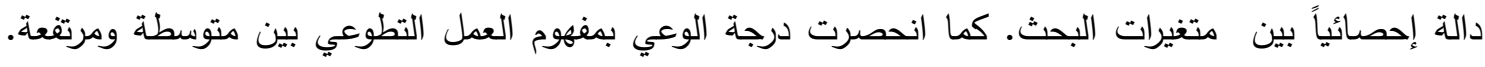

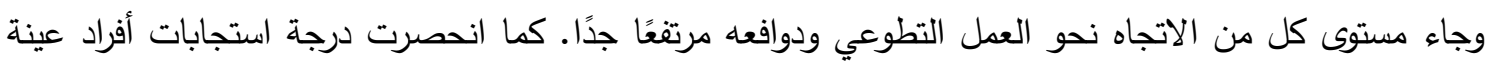

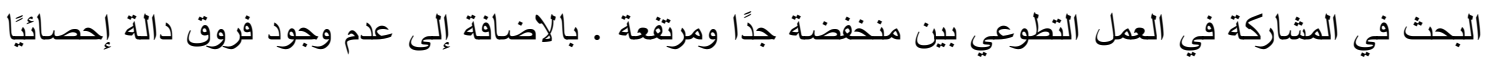

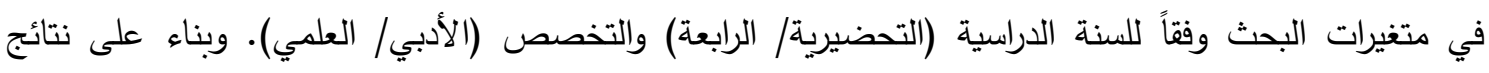

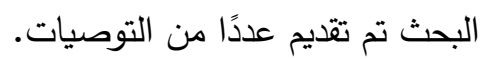
كلمات مفتاحية: ثقافة العطل التطوعي - الاتجاه نحو العطل التطوعي - دوافع العمل التطوعي - المشاركة في العمل التطوعي.

وتتقدم الباحثة بالثكر لعمادة البحث العلمي على

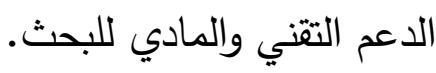

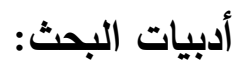

نعيش الآن في زمان تتلاحق فيه موجات التغير

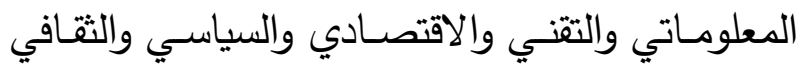
والاجتماعي والحضاري، هذا الزمان الذي صار فيه

\section{المقدمة}

تم تمويل هذا المشروع ضمن الأبحاث المتيزة

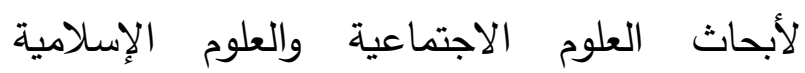
واللغويات من قبل عمادة البحث العلمي (DSR) جامعة جدة، تحت منحة رقم (UJ-20-023-SAI) 
التطوعي في واقع الحال يمثل منفعة للفرد ذاته حيث يشبع حاجته ودوافعه للعطاء، كما أنه يعطي الإنسان الذي يزاوله فرصة لتحقيق حاجاته الاجتماعية عن طريق تكوين علاقات صداقة مع المتطوعين الآخرين. ومن ثم يستطيع بتحقيقه هذه الحاجة أن ينتقل وفقا لهرم ماسلو إلى حاجة تقدير الذات وهي شعور الفرد بالثقة وحصوله على التقدير من الآخرين بما يشعره بمكانته وقيمته بما لديه من إمكانات مما يعينه على تحقيق أهداف العمل التطوعي. ولقد حثنا ديننا الإسلامي الحنيف على الإكثار من

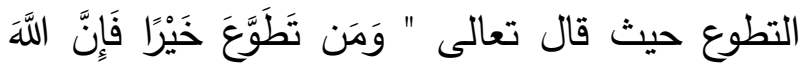

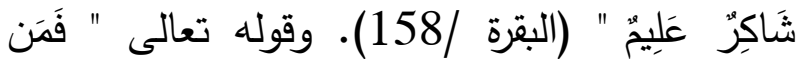

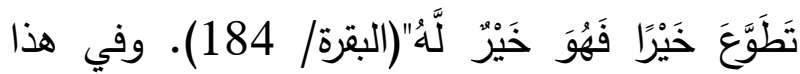
إثارة للأثر النفسي الذي يتركه العمل التطوعي في الني نفس الإنسان من راحة وشعور بالاعتزاز والثقة بالنفس. ومن نعم الله تعالى على بعض خلقه أنه

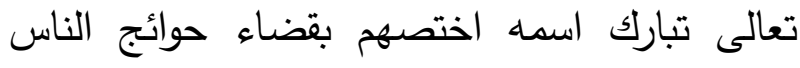
حببهم في الخير وحبب الخير إليهم أولئك هم تهاء الآمنون من عذابه يوم القيامة. وعليه فإن العمل التطوعي بعد قيمة إنسانية تسهم في غرس العديد من القيم والمثل الإنسانية في المجتمعات إذا ما تم استثارة الدافعية لاى كافة أفراد المجتمع وحفزهم تجاهه وتكوين اتجاهات إيجابية نحوه عن طريق توعيتهم بأهيته ودوره في النهوض ونه بالأمة. ومن هذا المنطلق فإننا بحاجة ماسة للعمل التطوعي والاهتمام به باعتباره أحد مجالات ومعالم
العالم بوتقـة ينصـهر فيها كل مستحدث ومستغرب ومستهجن ، زمـن يفرض علينـا ضـغوطه وصـراعاته اللامحدودة ، والانغمـاس والاستغراق في مخرجاته، والخنوع والاستسلام والوهن، وسط هذا الزخم لا بد لنا من أسـاليب، استراتيجيات، طرق أخرى نستخدمها، نتعامل بها ومن خلالها لمواجهة هذا الواقع بصبر ومثابرة وقدرة واقتدار وتفاعل وتتـاغم مـع معطياتـه ومتتاقضاته حتى نستطيع التواؤم والتوافق والانسجام معه بما لا يتعارض وثوابت منطلقاتتا وعقيدتنا الحقة التي لا يزيــن عنهـا إلا كُـلُ هالـك - عقيـدة الـدين

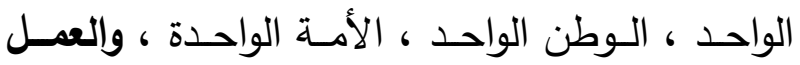

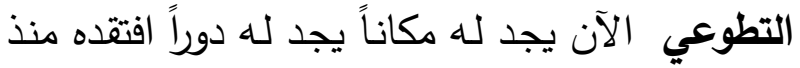
زمن - في ظل تضخم الأنا وتضاؤل النحن في ظل

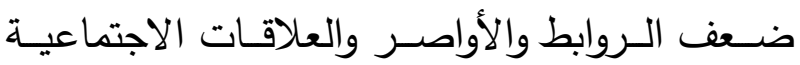

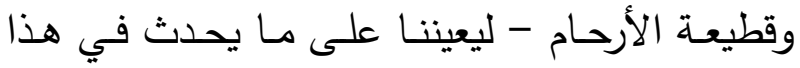
الزمان بالعمل على تقويـة الروابط الاجتماعية بين

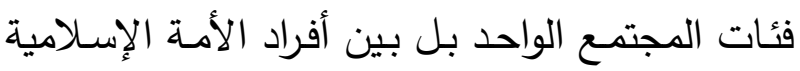

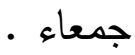
ويعد العمل التطوعي ظاهرة اجتماعية تختلف في أشكالها ومجالاتها وطريقة أدائها لتسجم مع الثقافات والمعتقدات الدينية لكل مجتمع ولكل عصر، ويقوم بصفة أساسية على توجه الإنسان ورغبته ودوافعه الذاتية كون الإنسان كائن اجتماعي بطبعه يرغب في أن يكون محبوبا ومقبولا من الآخرين عن طريق انتمائه لهم ومشاركتهم لما يعتتقون من مبادئ وقيم

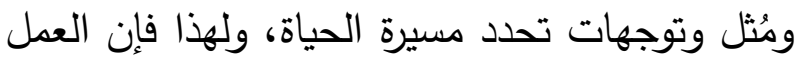


صدرت لائحة الجمعيات والمؤسسات الخيرية عام 1410هـ، وبتضافر الجهود الحكومية والأهلية أصبح للعمل الاجتماعي مكانته في خطط التنمية وبرامج الدولة التي ركزت على أن يكون الإنسان السعودي وسيلة التتمية وغايتها. (زهران، 2005) وعلى الرغم من أن حيوية المجتمع أو ركوده رهن إنهان بمستوى الثقافة السائدة لدياه، وثقافة التطوع جزعًا لا لا يتجزأ من مفهوم الثقافة بالمعنى العام لهذا فإن مدى لدى الإقبال على العمل التطوعي والمشاركة في فعالياته يتوقف على انتثار ثقافة التطوع في البيئة الاجتماعية، إلا أن الأدبيات في هذا المجال تثير

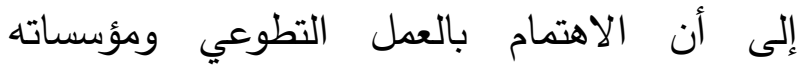

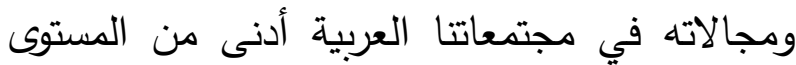
المطلوب، ويرجع السبب في ذلك إلى غياب ثقافة التطوع لاى الكثير من الأفراد ، وعدم إدراك

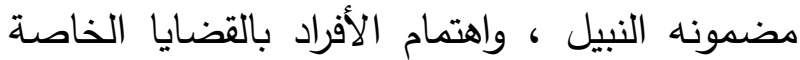

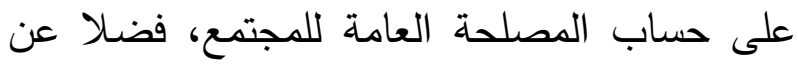
وجود عدة معوقات تعترض العاملين في مجاله (حجازي ومحمد، 2011). ومما يدلل على ذلك أيضاً نتائج دراسات المالكي (2010) التي أظهرت أن نسبة 50.6\% من عينة الدراسة من طالبات جامعة أم القرى وافقوا على وجود آثار سلبية على انى المتطوعة وهذا يدل على الاتجاه السلبي نحو العمل التطوعي. ودراسة الثناوي (2010) التي بينت أن نسبة 81.3\% لم يشاركوا في عمل تطوعي. ودراسة حجازي ومحمد (2011) توصلت إلى أن نسبة
التتمية الاجتماعية في المجتمع. لذا فقد ربطت وزارة العمل بالمملكة العربية السعودية برامجها بخطط التتمية بإشرافها على الجمعيات والمؤسسات الاجتماعية في مجال العمل التطوعي. ومن ثم فهي تعمل على تكوين رأي اجتماعي مستتير لتعبئة الجهود واستثمار الطاقات وتحويل قواه البشرية إلى لى لى قوى منتجة تعتمد على نفسها لتحقيق النمو

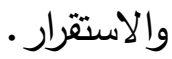

وقد أظهرت التجارب أن بعض الأجهز الرسمية لا تستطيع وحدها تحقيق كافة غايات خطط ومشاريع التتمية مهما كانت امكانات تلك الأجهزة دون المشاركة التطوعية الفعالة للمواطنين والجمعيات الأهلية التي يمكنها الإسهام بدور فاعل في عمليات

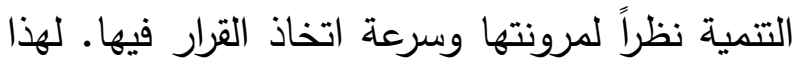
برز دور التطوع في إكمال الدور الذي تقوم به المؤسسات الحكومية إلى جانب مؤسسات القطاع الخاص في المجالات التتموية. (الثايجي، 2007، والحربي، 2014، وعودة، 2017) ولقد أولت المملكة العربية السعودية الاهتمام بالعمل التطوعي، حيث قامت وزارة العمل والثئون الاجتماعية التي تأسست عام 1380هـ بإنشاء أول مركز للتتمية الاجتماعية في الدرعية، وقامت بتثكيل لجان أهلية متخصصة في مجالات العمل التطوعي، تلا ذلك إنشاء أول جمعية تعاونية، كما قامت الوزارة بتظيم صناديق البر الخيرية وسجلتها كجمعيات خيرية وفق لوائح نظمت عملها إلى أن 
83.8 من طالبات الجامعة لـ يشاركن في الأخرى، وأي تغير يطرأ على أحد المتغيرات لا بد الأعمال التطوعية. ودراسة الكندري (2016) كان أن ينعكس على بقية المتغيرات، وهذه المتغيرات من نتائجها أن 55.7\% من طلبة كلية التربية لم هي: الوعي بمفهوم العمل التطوعي والاتجاه نحوه

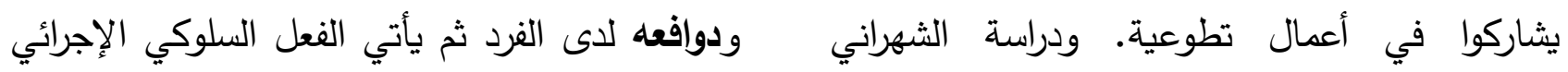
(2017) أظهرت أن نسبة 85.8\% من طلبة الذي يعبر عنه بالمشاركة في الأعمال التطوعية

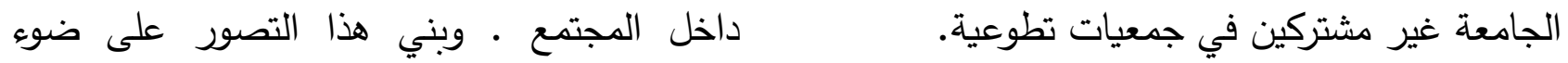

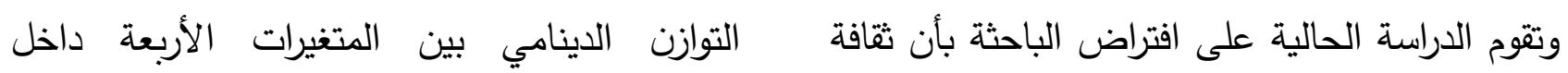
العمل التطوعي تثتمل على أربعة متغيرات أو الثخصية الإنسانية. ويمكن تمثيل هذا التصور في لتئي مكونات مرتبطة بعضها ببعض ذات علاقات تأثير الشكل (1).

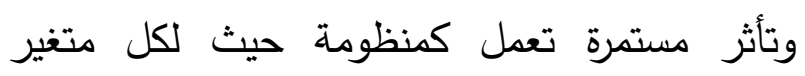
وظيفة وهذه الوظيفة مكملة لوظائف المتغيرات

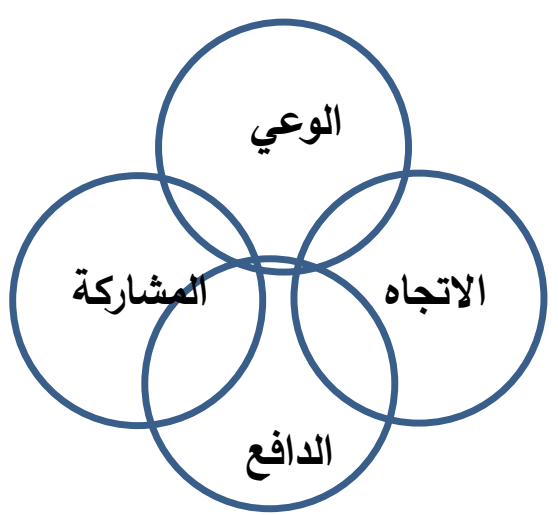

شكل (1) مكونات ثقافة العمل التطوعي

ومما يؤكد هذا التصور نظرية الدور التي ترتكز على محاولات التيار المعرفي خلال السنوات (1950أن حاجات الانسان ودوافعه وقيمه واتجاهاته 1970) في تفسير السلوك الاجتماعي للإنسان،

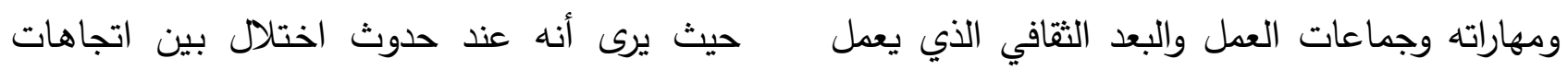
فيه، تؤثر على دوره وأن ممارسته لدوره الرسمي الإنسان وسلوكاته فان الدوافع تؤدي دورًا في القضاء لئهل

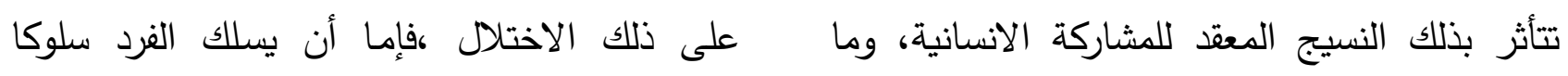

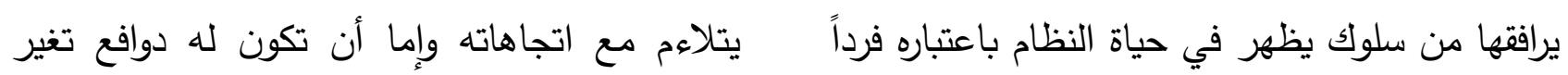
يشغل دوراً معيناً في النظام الاجتماعي. (كريب، اتجاهاته وفق سلوكياته.

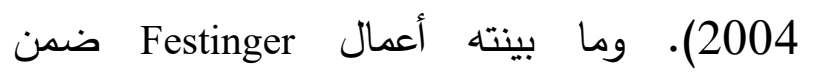


الآخرين، وبقدرتهم على التأثير والتأثر بهم. وعندما تتحول النظرة إلى العالم من الوضع الأولى للتمركز

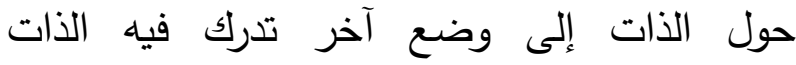
باعتبارها جزءاً لا يتجزأ من كل أكبر، يصبح الناس لترك

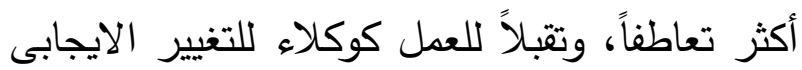
Schlitz, ) فى مجتمعاتهم المباشرة وما وراءها. Vieten \& Miller, 2010)

وتمثل الاتجاهات نتاجاً اجتماعياُ ثقافياً حيث ترتبط بقيم المجتمع ومعاييره، وتتكون من المعارف والخبرات والمعتقدات التي اكتسبها الفرد من خلال إدراكه الواعي لبيئته الاجتماعية والتفاعل والتتاغم معها، بالإضافة إلى مشاعره ورغباته تجاه موضوع لئه

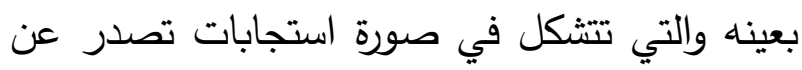
الفرد في مواقف الحياة التي يتعرض لها وقد تكون هذه الاستجابات ايجابية أو سلبية وفق قبوله أو لون رفضاه لموضوع معين.

ويؤثر الاتجاه بدوره على مشاركة الثباب في العمل التطوعي تأثيراً واضحاً ايجابًا أو سلبًا، كما تؤثر

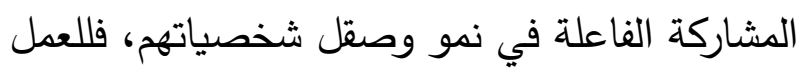
التطوعي العديد من الفوائد التي تعود بالنفع والفائدة

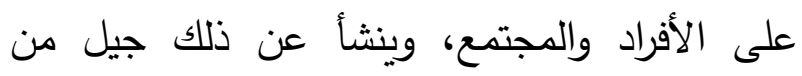

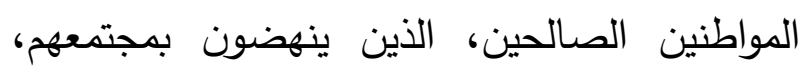

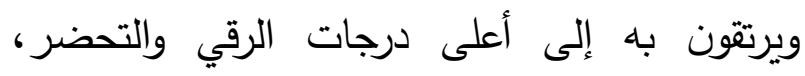

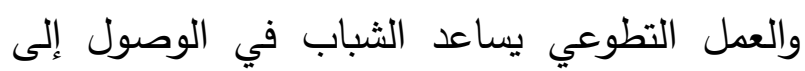
الإحساس بالأمن والسِلم النفسي عن طريق التئي استثمار أوقات فراغهم بطريقة مفيدة (برقاوي ، 2008 : 66- 67) ؛ وهذا ما أكدته نتائج دراسة إبراهيم
كما يعضد هذا التصور ما يراه أصحاب نظرية التفسير الديناميكي للاتجاهات أن الاتجاهات تعتبر وسط ديناميكي يقع بين العمليات النفسية الأساسية والسلوك الذي يصدر من الفرد، والاتجاهات بهذا المفهوم الديناميكي تتظم الدوافع والادراك للفرد والعوامل النفسية الأخرى تنظيماً متسقاً يساير البيئة في تأثيرها ويؤثر بدوره فيها. (وليم، 2013) وحينما ننظر إلى العمل التطوعي كسلوك نجد له العديد من الدوافع التي تختلف باختلاف الأفراد وخلفياتهم الثقافية والاجتماعية والدينية ومن هذه

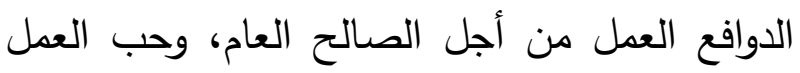

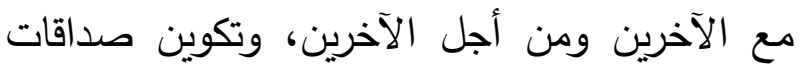
وكسب احترام وتقدير الآخرين، من أجل تكوين علاقات اجتماعية واستثمارها، واكتساب مهارات وخبرات جديدة قد يحتاجها المتطوع مستقبلا في

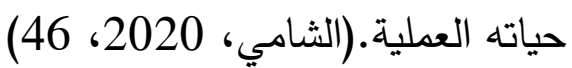
ويعتبر الوعي الاجتماعي بمثابة الإدراك الواعى

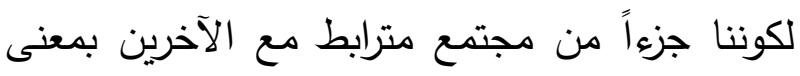

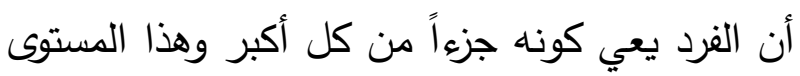
يعى فيه الفرد كيف يتأثر بالآخرين، وكيف يمكن أن أن الن

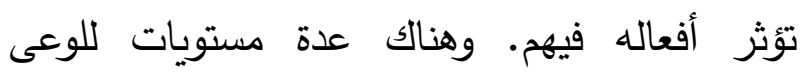

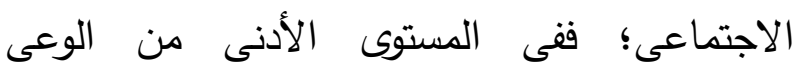
الاجتماعى، نجد نقصاً واضحاً فى وعى الأفراد

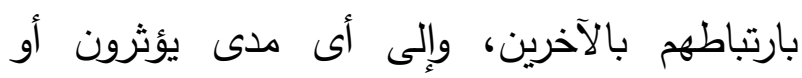

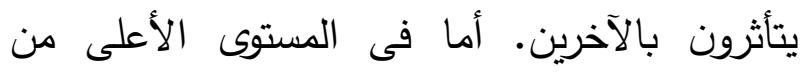

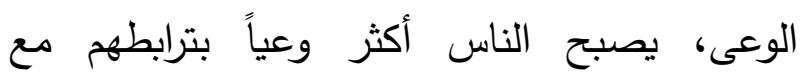


عنه دراسة كل من مقدم ومحمداتني (2020) من المعيقات الاجتماعية التي تعيق مشاركة المرأة في العمل التطوعي من غياب التثجيع من المجتمع،

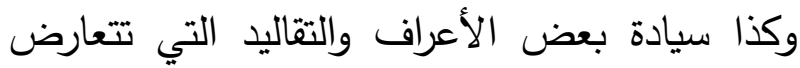

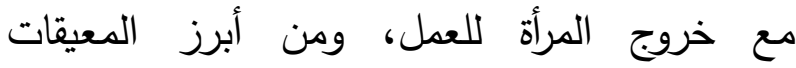
التتظيمية عدم وجود مؤسسات وهيئات تدعم العمل التطوعي النسوي، ومن أهم المعيقات الذاتية

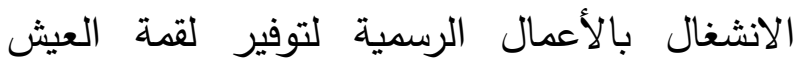

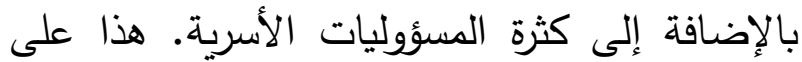
الرغم من أن المملكة أصبحت طرفا فاعلاً في تفعيل جهود العمل التطوعي بما يتسق مع طبيعتها على الصعيدين الإقليمي والدولي، من خلال إطلاق العديد من المبادرات المهمة، التي تقدم خدمات مجتمعية في مختلف المجالات الإغاثية والصحية والتعليمية والبيئية والثقافية.

من هذا المنطلق بات من الضروري الاهتمام بدارسة ثقافة التطوع كونه ضرورة حضارية لكي تتمكن الأمة من الإسهام بفاعلية في بناء وصوغ الخطاب العالمي حول ثقافة التطوع، نظراً لامتلاكها تراثاً غنياً بالقيم والمبادئ والمعايير والأخلاقيات التي يمكن أن تستقيد منها البشرية.

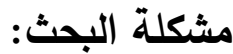
مما سبق تتحدد مشكلة البحث الحالي في

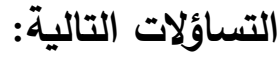

(2006) بالإضافة إلى اكتساب المزيد من المهارات والخبرات. ودراسة خليل (2001) التي توصلت إلى أهمية الجماعات التطوعية في تتمية المسئولية الاجتماعية لأعضائها؛ ودراسة (Ohsaka,2008) التي أظهرت أن العمل التطوعي يوفر الفرص التصاعل للمتطوعات من النساء في المشاركة في الأدوار الاجتماعية المختلفة وتتمية العلاقات الاجتماعية لايهن. ولا تزال الجهود التطوعية في المملكة العربية السعودية والعالم العربي بشكل عام دون المستوى المطلوب حيث تثير الأدبيات إلى أن مستوى العمل التطوعي ما يزال محدوداً، حيث يركز على إلى لان المجالات الدعوية والاجتماعية وتقديم الخدمات

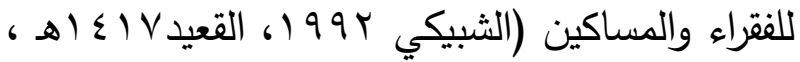

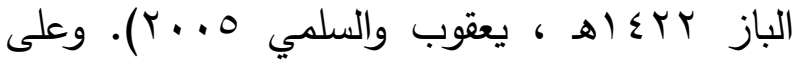
الرغم من محورية دور المرأة في العمل التطوعي فإن ثقافة التطوع لاى الإناث ما زالت دون المستوى المطلوب ولم تلق العناية اللازمـة لتفعيل دورها وإثراء خبراتها بما يتسق مـع طبيعتها أو لوجود معوقات تحول دون ممارستها للعمل التطوعي، ويؤيد ذلك ما توصلت إليه نياز (2012)، والقريشي (2018) من عدم وعي المجتمع بأهمية العمل التطوعي، وضعف اللوائح والأنظمة الخاصة به، وعدم إلحاق المتطوعات بدورات تدريبية، وعدم وضع المتطوعة في المكان الملائم لقدراتها. بالإضافة إلى جهل المجتمع بأهمية العمل التطوعي، وما كثفت لفتان 
4. الاختلاف في درجة استجابات أفراد عينة البحث في لدوافع نحو العمل التطوعي. 5. الاختلاف في درجة استجابات أفراد عينة البحث في المشاركة في العمل التطوعي. 6. التباين في درجة الوعي بمفهوم العمل التطوعي والاتجاه نحوه ودوافعه والمشاركة فيه لاى أفراد عينة البحث وفقاً للسنة الدراسية (التحضرية/ الرابعة).

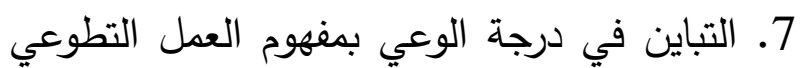
والاتجاه نحوه ودوافعه والمشاركة فيه لدى أفراد عينة

البحث وفقاً للتخصص الدراسي (علمي / أدبي). أهمية البحث: - أبحاث

تنبع أهمية البحث الحالي مما يلي:

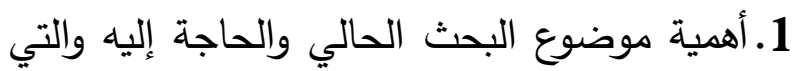
تتضح فيما يلي: ترني

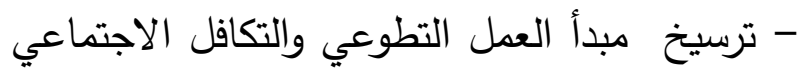
بين طبقات المجتمع كأحد المبادئ التي جاء بها الاسلام وحض عليها، واستثمارا لوقت الفراغ للمتطوعين وللعاطلين عن العمل، والحاجة إلى جعل العمل التطوعي ثقافة مجتمعية، واعتبار العمل التطوعي من أهم الوسائل المستخدمة في النهوض ولهي

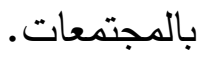
- كون العمل التطوعي يمثل أحد الاستراتيجيات التي يمكن الاعتماد عليها في تحسين مستويات النمو الأكاديمي للطلاب وتتمية مهاراتهم الثخصية الاعية فئين

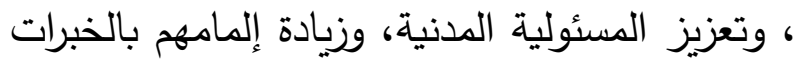

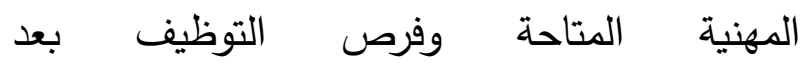
(Cnaan, Smith, Holmes, Haski-التخرج
1. ما طبيعة العلاقة الارتباطية بين كل من الوعي بمفهوم العمل التطوعي والاتجاه نحوه ودوافعه والمشاركة فيه لدى أفراد عينة الدراسة؟

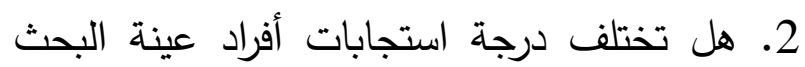
في الوعي بمفهوم العمل التطوعي ؟ 3. هل يختلف مستوى الاتجاه نحو العمل التطوعي

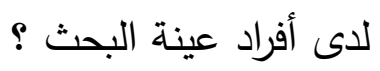
4. هل تختلف درجة استجابات أفراد عينة البحث في لدوافع نحو العمل التطوعي ؟ 5. هل تختلف درجة استجابات أفراد عينة البحث في المشاركة في العمل التطوعي ؟ 6. هل تتباين درجة الوعي بمفهوم العمل التطوعي والاتجاه نحوه ودوافعه والمشاركة فيه لاى أفراد عينة البحث وفقاً للسنة الدراسية (التحضرية / الرابعة)؟

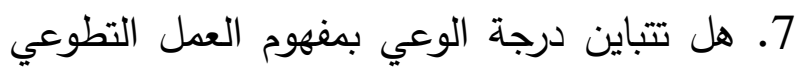
والاتجاه نحوه ودوافعه والمشاركة فيه لدى أفراد عينة البحث وفقاً للتخصص الدراسي (علمي / أدبي)؟

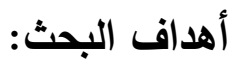
يهدف البحث الحالي إلى الكثف عن: 1. طبيعة العلاقة الارتباطية بين كل من الوعي إلى الوهيل

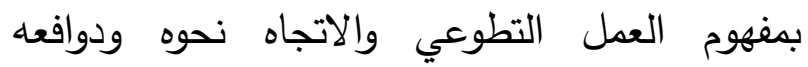
والمشاركة فيه لاى أفراد عينة الدراسة. 2. الاختلاف في درجة استجابات أفراد عينة البحث لـث بمفهوم العمل التطوعي. 3. الاختلاف في مستوى الاتجاه نحو العمل البحث

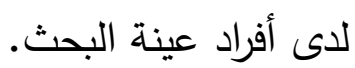


لاى طلاب وطالبات الجامعة نحو العمل التطوعي، إضافة إلى ضعف مشاركتهم وانخراطهم في مجالات العمل التطوعي بشكل عام • في حين أشارت نتائج

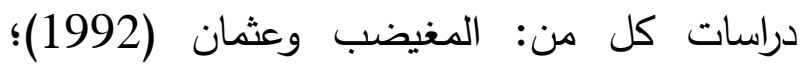
و Esmond (2001) ، حسين (2006) ، والمالكي (2013

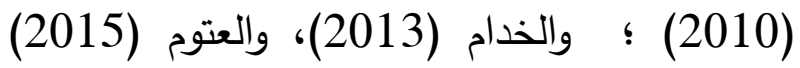
والألفي (2017) إلى أن اتجاهات شباب الجامعة اتسمت بالايجابية بشكل عام.

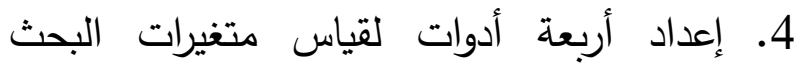
الحالي. مصطلحات البحث:

1.ثقافة العمل التطوعي: تعرف إجرائياً بأنها الوعي بمفهوم العمل التطوعي والاتجاه نحوه ودوافع الفرد التي تحرك سلوكه نحو المشاركة فيه من أجل الآخرين والمجتمع دون انتظار عائد مادي بثكل إرادي. وتستمد هذه الثقافة من قيم المجتمع دادئ الاسلامي ومبادئ المجتمع المدني الحديث. 2.الوعي بمفهوم العمل التطوعي: يعرف إجرائياً

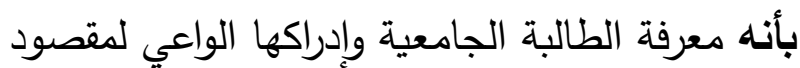

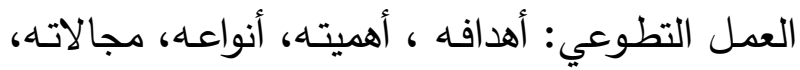

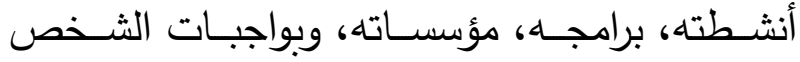
المتطوع وحقوقه.

3.الاتجاه نحو العمل التظوعي: يعرف إجرائياً بأنه الموقف الذي تتخذه الطالبة الجامعية إيجاباً أو سلباً

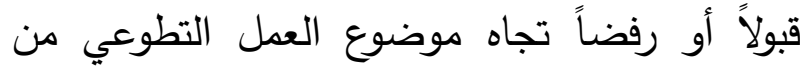
حيث استعدادها واستجابتها من خلاه وفل الأفكار والمشاعر والتصورات التي تؤمن بها نحو موضوع

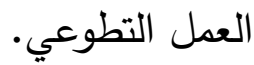

Leventhal \& Handy, 2010, 69) الاستعانة به في غرس القيم الأساسية في نفوس الطلبة، وترسيخ الهوية، ودعم القيم الدينية. (Grönlund,2012) - الاهتمام بثقافة العمل التطوعي كونها مطلبا من متطلبات الحياة المعاصرة وحاجة ملحة لمواكبة التتمية والتطور السريع في كافة مجالات الحياة، حيث يمثل العمل التطوعي أحد المؤشرات الدالة على تقدم الأمم وازدهارها ويسهم في بناء وتتمية المجتمع ونشر التماسك الاجتماعي بين المواطنين.

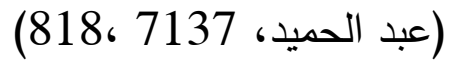
2. أهمية الفئة المستهدفة - عينة البحث الحالي من طالبات الجامعة حيث أكدت نتائج بعض البنه الدراسات كدراسات: (عبدالتواب، 2006؛2010, Daoud و 2008, Ohsaka) على ضرورة إشراك المرأة في العمل التطوعي وتمكين وضع المرأة في

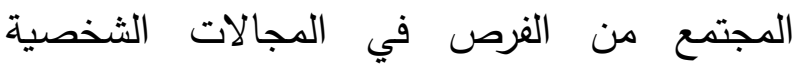
والعامة. كما أظهرت أن العمل التطوعي يوفر فئر

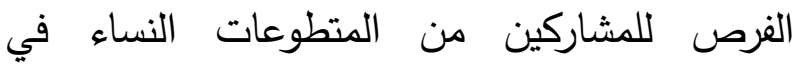
المشاركة في الأدوار الاجتماعية المختلفة وتتمية

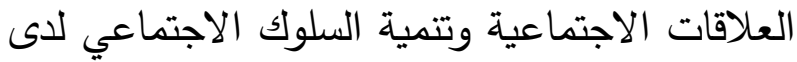

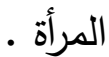

3. وجود تضارب في نتائج الدراسات السابقة من حيث اتجاه ومشاركة الثباب الجامعي في العمل التطوعي، فقد أشارت نتائج دراسات كل من: الباز

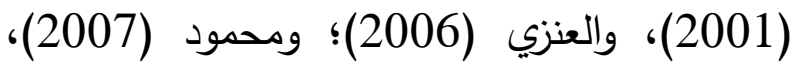
والنابلسي (2007)، والسلطان (2009)، وحجازي ومحمد (2011)، وعارف (2012)، والخدام (2013) وبرو (2015) إلى وجود اتجاهات سالبة 
2. مقياس الاتجاه نحو العمل التطوعي: يتكون في صورته الأولية من (15) فقرة، يجاب عنها باختيار

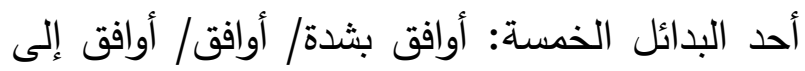
حد ما / غير موافق/ غير موافق بشدة. 3. مقياس دوافع العمل التطوعي: يتكون في صورته الأولية من (15) فقرة، يجاب عنها باختيار

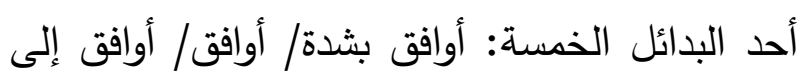
حد ما / غير موافق/ غير موافق بشدة.

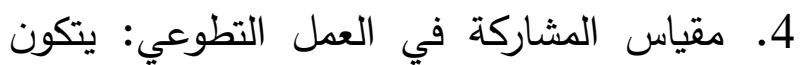
في صورته الأولية من (19) فقرة، يجاب عنها باختيار أحد البدائل الخمسة: كبيرة جدًا/ كبيرة/ متوسطة/ قليلة/ منعدمة. تم إعداد المقاييس الأربعة بعد الاطلاع على على الأدبيات المرتبطة بهذا المجال من أطر نظرية ودراسات سابقة كدراسات برقاوي (2008)، عيد (2009)، حجازي ودحمد (2011)، الخدام (2013)، برو (2015)، عبد العزيز (2019)، (100) الشامي (2020)، ومقدم وحمداتيي (2020). الخصائص السيكومتربة لنأدوات: الصدق تم استخدام الطريقتين التاليتين: 1. صـدق المحتـوى: تـم عـرض المقـاييس الأربعـة على عـدد (7) مـن المحكمـين المتخصصـين في أصول التربية الاسلامية وعلم النفس التربوي والقياس

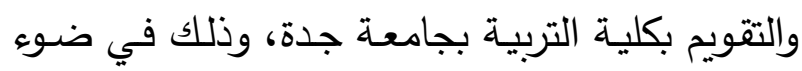
التعريفـات الإجرائيـة للمتغيـرات ، بهدف إبداء الـرأي حول تطـابق فقرات كل مقيـاس على حدة مـع مـا تقيسه إلى جانب سلامتها من حيث الصياغة اللغويـة

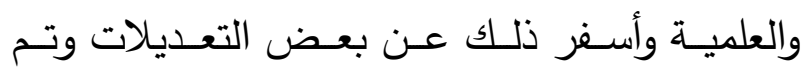

4.دوافع العمل التطوعي: تعرف إجرائياً بأنها مجموعة من الرغبات الداخليّة والخارجيّة التي تعمل إنل على توجيه وتحريك سلوك الطالبة الجامعية نحو

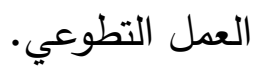
6.المشاركة في العمل الخيري: تعرف إجرائياً بأنه مشاركة الطالبة الجامعية في مختلف أوجه العمل التطوعي داخل المجتمع السعودي. منهج البحث وإجراء اته : منهو منهج البحث: اعتمد البحث المنهج الوصفي بثقيه الارتباطي والمقارن. عينة البحث : عنمان تكونت العينة الاستطلاعية من (50) طالبة، بمتوسط عمري (22.36) وانحراف معياري (2.44) ؛ واستخدمت درجات هذه العينة في التحقق من الخصائص السيكومترية ل لأدوات البحث. أما العينة الأساسية فتكونت من (150) طالبة اختيرت بطريقة عشوائية (68) طالبة بالسنة التحضيرية ، (82) طالبة بالسنة الرابعة ، (39) طالبة من التخصصات الأدبية و(43) طالبة من التخصصات العلمية بجامعة جدة في العام الدراسي1441هـ /2020م ،بمتوسط عمري (22.68) وانحراف معياري .(2.79) أدوات البحث: قامت الباحثة بإعداد أربعة مقاييس وهي: 1. مقياس الوعي بالعمل التطوعي: يتكون في صورته الأولية من (15) فقرة، يجاب عنها باختيار

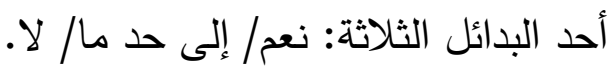


2. الإتسـاق الـاخلي: تم تطبيق المقاييس الأربعـة الارتباط بين كل فقرة والدرجة الكلية للمقياس الذي

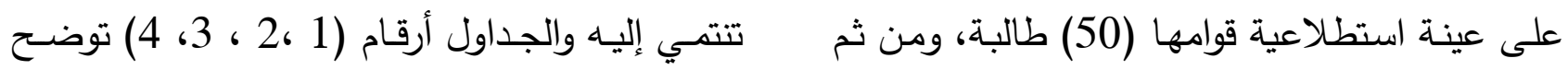

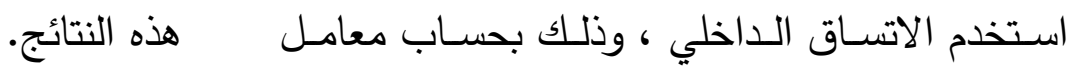
جدول (1) معاملات الارتباط بين الفقرات والدرجة الكلية لمقياس الوعي بمفهوم العمل التطوعي

\begin{tabular}{|c|c|c|c|}
\hline قيم معاملات الارتباط & أرقام الفقرات & قيم معاملات الارتباط & أرقام الفقرات \\
\hline $.72^{* *}$ & 9 & $.49^{* *}$ & 1 \\
\hline $.52^{* *}$ & 10 & $.44^{* * *}$ & 2 \\
\hline $.51^{* *}$ & 11 & $.43^{* *}$ & 3 \\
\hline $.44^{* *}$ & 12 & $.42^{* *}$ & 4 \\
\hline $.39^{* *}$ & 13 & $.72^{* * *}$ & 5 \\
\hline $.53^{* *}$ & 14 & $.68^{* *}$ & 6 \\
\hline $.45^{* *}$ & 15 & $.66^{* *}$ & 7 \\
\hline & & $.58^{* *}$ & 8 \\
\hline
\end{tabular}

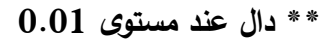

يتضـح من الجدول (1) أن جميع قيم معاملات ارتباط الفقرات بالدرجة الكلية لمقياس الوعي بمفهوم العمل التطوعي دالة إحصائيا عند مستوى (0.01). جدول (2) معاملات الارتباط بين الفقرات واللارجة الكلية لمقياس الاتجاه نحو العمل التطوعي

\begin{tabular}{|c|c|c|c|}
\hline قيم معاملات الارتباط & أرقام الفقرات & قيم معاملات الارتباط & أرقام الفقرات \\
\hline $.77^{* *}$ & 9 & $.41^{* *}$ & 1 \\
\hline $.59^{* *}$ & 10 & $.68^{* *}$ & 2 \\
\hline $.68^{* *}$ & 11 & $.77^{* *}$ & 3 \\
\hline $.61^{* *}$ & 12 & $.68^{* *}$ & 4 \\
\hline $.64^{* *}$ & 13 & $.64^{* *}$ & 5 \\
\hline $.67^{* *}$ & 14 & $.54^{* *}$ & 6 \\
\hline $.72^{* *}$ & 15 & $.67^{* * *}$ & 7 \\
\hline & & $.67^{* * *}$ & 8 \\
\hline
\end{tabular}

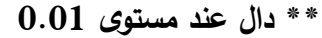

يتصـح مـن الجدول (2) أن جميع قيم معـاملات ارتباط الفقرات بالدرجـة الكليـة لمقيـاس الاتجـاه نحو العمل التطوعي دالة إحصائيا عند مستوى (0.01). 
جدول (3) معاملات الارتباط بين الفقرات والدرجة الكلية لمقياس دوافع العمل التطوعي

\begin{tabular}{|c|c|c|c|}
\hline قيم معاملات الارتباط & أرقام الفقرات & قيم معاملات الارتباط & أرقام الفقرات \\
\hline $.73^{* * *}$ & 9 & $.35^{*}$ & 1 \\
\hline $.45^{* *}$ & 10 & $.54^{* *}$ & 2 \\
\hline $.437^{* *}$ & 11 & $.62^{* *}$ & 3 \\
\hline .15 & 12 & $.53^{* *}$ & 4 \\
\hline $.63^{* *}$ & 13 & $.51^{* *}$ & 5 \\
\hline $.66^{* *}$ & 14 & $.50^{* *}$ & 6 \\
\hline $.71^{* *}$ & 15 & $.75^{* *}$ & 7 \\
\hline & & $.62^{* *}$ & 8 \\
\hline
\end{tabular}

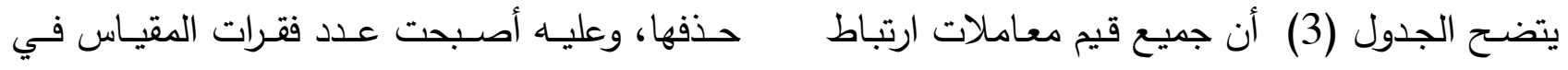

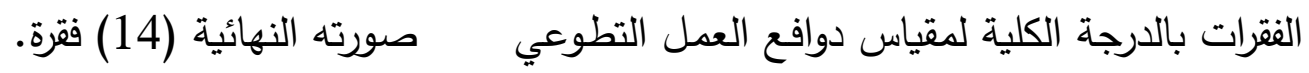

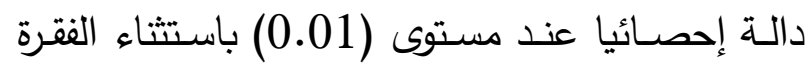

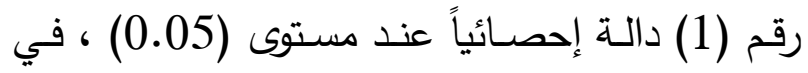

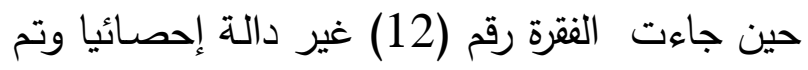
جدول (4) معاملات الارتباط بين الفقرات والدرجة الكلية لمقياس المشاركة في العمل التطوعي

\begin{tabular}{|c|c|c|c|}
\hline قيم معاملات الارتباط & أرقام الفقرات & قيم معاملات الارتباط & أرقام الفقرات \\
\hline $.54^{* * *}$ & 11 & $.65^{* *}$ & 1 \\
\hline $.63^{* *}$ & 12 & $.75^{* *}$ & 2 \\
\hline $.53^{* *}$ & 13 & $.55^{* *}$ & 3 \\
\hline .17 & 14 & $.79^{* *}$ & 4 \\
\hline $.39^{* * *}$ & 15 & $.46^{* *}$ & 5 \\
\hline .25 & 16 & $.39^{* * *}$ & 6 \\
\hline $.52^{* *}$ & 17 & $.67^{* *}$ & 7 \\
\hline $.47^{* *}$ & 18 & $.53^{* *}$ & 8 \\
\hline .27 & 19 & $.58^{* * *}$ & 9 \\
\hline & & $.70^{* * *}$ & 10 \\
\hline
\end{tabular}




$$
\text { يتضـح مـن الجدول (4) أن جميـع قيم معساملات انانيا : الثبات }
$$

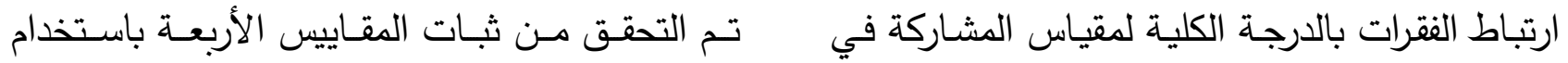

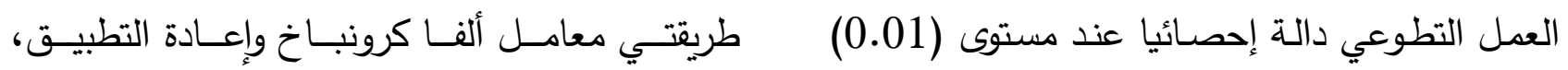

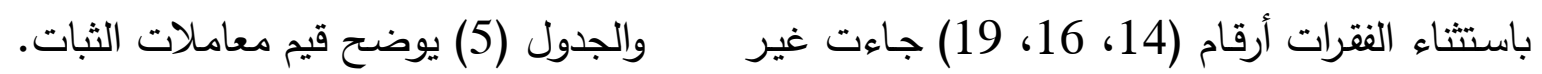
دالة إحصائياً وتم حذفها. وعليه أصبحت عدد فقرات المقياس في صورته النهائية (16) فقرة.

جدول (5) قيم معاملات ثبات مقاييس البحث

\begin{tabular}{|c|c|c|c|}
\hline إعادة اتطبيق(ن =50) & معامل ألفا كرونباخ & اسم المقياس & 5 \\
\hline $.87 * *$ & .81 & الوعي بمفهوم العمل التطوعي & 1 \\
\hline $.85^{* *}$ & .85 & الاتجاه نحو العمل التطوعي & 2 \\
\hline $.81 * *$ & .89 & دوافع العمل التطوعي & 3 \\
\hline $.86 * *$ & .88 & المشاركة في العمل التطوعي & 4 \\
\hline
\end{tabular}

يتضح من الجدول (5) أن جميع قيم معاملات الثبات جاءت مرتفعة، لذا يمكن القول بأن الدقاييس الأربعة تتمتع بدرجة عالية من

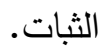

التطوعي والاتجاه نحوه ودوافعه والمشاركة فيه لدى

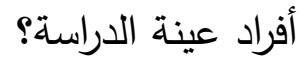

وللاجابة على هذا السؤال تم استخدام معامل ارتباط

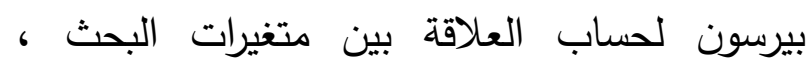
ويوضح الجدول (6) هذه النتائج.
من جميع الإجراءات السابقة تم التأكد من صلاحية المقاييس للتطبيق علي العينة الأساسية للبحث. نتائج البحث: نتائج السؤال الأول: وينص السوال الأول على : " ما طبيعة العلاقة الارتباطية بين كل من الوعي بمفهوم العمل 
جدول (6) معاملات الارتباط البينية بين متغيرات ثقافة العمل التطوعي المدروسة

\begin{tabular}{|c|c|c|c|c|}
\hline العمل التطوعي المشاركة في & دوافع العمل & العمل التطوعي & العمل التطوعي بمفهوم & المتغيرات \\
\hline & & & - & الوعي بمفهوم العمل التطوعي \\
\hline & & - & $.55^{* *}$ & الاتجاه نحو العمل التطوعي \\
\hline & - & $.78 * *$ & $.56^{* *}$ & دوافع العمل التطوعي \\
\hline- & $51 * *$ & $.50 \% *$ & $.62 * *$ & المشاركة في العمل التطوعي \\
\hline
\end{tabular}

0.01 * : دال عند مستوى

يتضح من الجدول (6) وجود علاقات ارتباطية خلال عملية التدعيم الاجتماعي موجبة دالة إحصائياً عند مستوى (0.01) بين كل الاجتماعية، ويشكل هذا الوعي المكون المعرفي من الوعي بمفهوم العمل التطوعي والاتجاه نحوه لاتجاه من مجموعة المعارف والأحكام والمعتقدات ودوافعه والمشاركة فيه لدى أفراد عينة البحث، وبهذا والقيم والآراء حول موضوع العمل التطوعي، وكلما تتحقق صحة الفرضية الأولى وهذه النتيجة تؤيد ادوت معرفته بالموضوع كان اتجاهـ أكثر تحديداً،

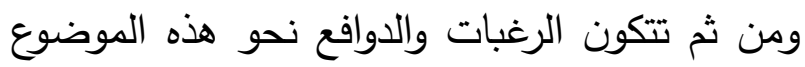

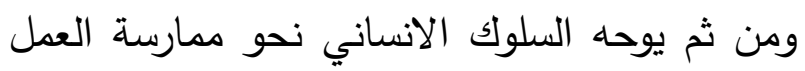
التطوعي كفرد داخل منظومة مجتمعية.

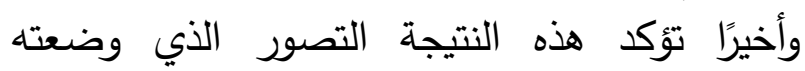
الباحثة لمكونات ثقافة العمل التطوعي. نتائج السؤال الثاني: التصور المقترح في شكل (1) السابق. وتؤيد هذه النتيجة ما يراه أصحاب نظرية التفسير الديناميكي للاتجاهات أن الاتجاهات تعتبر وسط ئلناب ديناميكي يقع بين العمليات النفسية الأساسية والسلوك الذي يصدر من الفرد، والاتجاهات بهذا المفهوم الديناميكي تتظم الدوافع والادراك للفرد وتنص السؤال الثاني على : " هل تختلف درجة

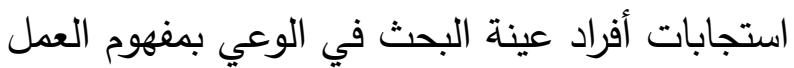
التطوعي ؟." ولإجابة على هذا السؤال تم حساب المتوسطات الحسابية والانحرافات المعيارية لاستجابات أفراد العينة على مقياس الوعي بمفهوم العمل التطوعي، ولتفسير استجابات أفراد الدراسة فقد تم الحصول على الوزن النسبي للمتوسطات باستخدام المعادلة

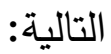
والعوامل النفسية الأخرى تنظيماً متسقاً يساير البيئة في تأثيرها ويؤثر بدوره فيها. (وليم، 2013). وأيضًا ما تقره نظرية الدور من أن حاجات الانسان ودوافعه وقيمه واتجاهاته ومهاراته وجماعات العمل والبعد الثقافي الذي يعمل فيه، تؤثر على دوره وأن ممارسته لدوره الرسمي تتأثر بذلك النسيج المعقد للمشاركة الانسانية، وما يرافقها من سلوك يظهر في حياة

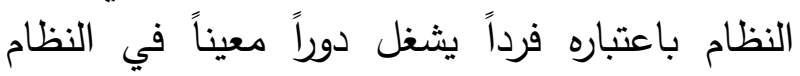
الاجتماعي. (كريب، 2004) طول الفئة = (الحد الأعلى لاختيارات الإجابة الحد الأدنى لاختيارات الإجابة) / عدد الفئات وتؤكد هذه النتيجة دور عامل الادراك الواعي كمحدد أولي لتطوير الاتجاهات لدى الفرد والذي يتكون 
2- عندما يكون المتوسط الحسابي للاستجابات

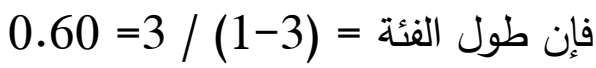

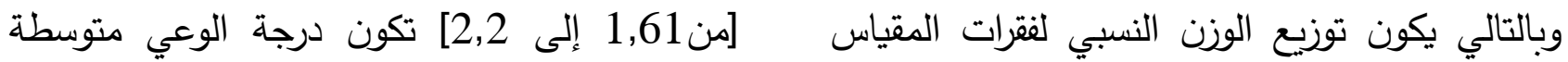
والتي تقابل الاجابة إلى حد ما. وفق التدريج الثلاثي التالي: توني التوزن 3- عندما يكون المتوسط الحسابي للاستجابات 1 - عندما يكون المتوسط الحسابي للاستجابات

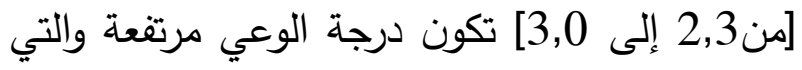

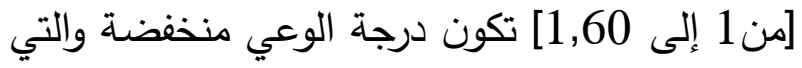

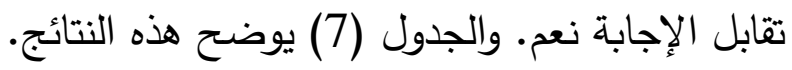

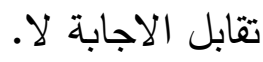

جدول (7) المتوسطات الحسابية والانحرافات المعيارية لاستجابات افراد العينة حول الوعي بمفهوم العمل التطوعي

\begin{tabular}{|c|c|c|c|c|}
\hline درجة الوعي & الانحراف & المتوسط الحسابي & 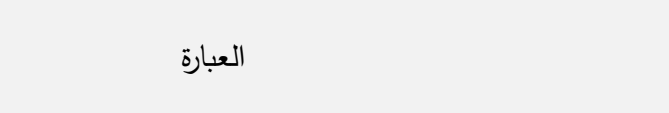 & 5 \\
\hline 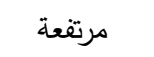 & 1.47 & 2.95 & أعرف المقصود بالعمل التطوعي . & 1 \\
\hline مرتفعة & .63 & 2.67 & لاي علم بأهداف العمل التطوعي . & 2 \\
\hline مرتفعة & .29 & 2.91 & لاي علم بأهمية العمل التطوعي . & 3 \\
\hline 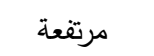 & .31 & 2.91 & لدي علم بفوائد العمل التطوعي. & 4 \\
\hline متوسطة & .53 & 2.21 & لدي علم بأنواع العملالتطوعي . & 5 \\
\hline متوسطة & .77 & 2.20 & لدي معرفة بمجال العمل التطوعي الديني. & 6 \\
\hline متوسطة & .70 & 2.29 & لدي معرفة بمجال العمل التطوعي الصحي. & 7 \\
\hline 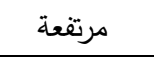 & .71 & 2.47 & لدي معرفة بججال العمل التطوعي الاجتماعي. & 8 \\
\hline متوسطة & .72 & 1.93 & لدي معرفة بمجال العمل التطوعي الثقافي. & 9 \\
\hline متوسطة & .77 & 2.22 & لدي معرفة بمجال العمل التطوعي الإغاثي. & 10 \\
\hline متوسطة & .64 & 1.85 & لدي علم بالجمعيات التطوعية العاملة بالمجتمع السعودي. & 11 \\
\hline 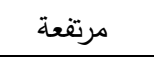 & .57 & 2.34 & لدي معرفة بواجبات الثخص المتطوع. & 12 \\
\hline متوسطة & .60 & 1.97 & لدي معرفة بحقوق الثخص المتطوع . & 13 \\
\hline متوسطة & .55 & 1.71 & لدي علم بقيادات العمل التطوعي في المجتمع السعودي. & 14 \\
\hline متوسطة & .49 & 1.79 & أعرف البرامج والأنثطة التي تطرحها الجمعيات التطوعية . & 15 \\
\hline متوسطة & .534 & 2.23 & \multicolumn{2}{|c|}{ المتوسط العام } \\
\hline
\end{tabular}

يتضح من الجدول (7) أن درجة الوعي بمفهوم 2030 بالوصول إلى مليون منطوع من خلال تعظيم الأثر التنموي للجامعة من خلال تعزيز المسؤولية الاجتماعية لمنسوبيها، تعزيز الصورة الذهنية لجامعة

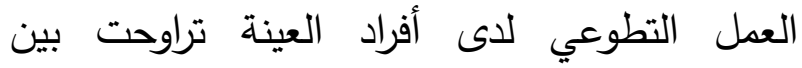
متوسطة ومرتفعة، وجاء المتوسط العام متوسط. جدة في المجتمع، التثقيف وتطوير ممارسات العمل التطوعي ونشر الوعي بأهميته بين منسوبي الجامعة،

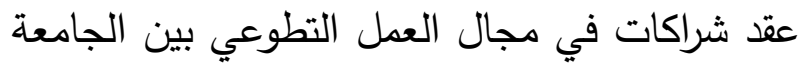
والجهات الحكومية والخاصة ومؤسسات المجتمع ويمكن تفسير هذه النتيجة إلى زيادة درجة الوعي لاى طالبات جامعة جدة وخاصة في الآونة الأخيرة حيث أنشأت الجامعة مركز للعمل التطوعي يهدف إلى المشاركة في تحقيق مستهدف رؤية المملكة 
المدني ومنظمات الأعمال لتمكين منسوبي وطلاب 2013). كما بينت دراسة أبو زيد (2020) أن من

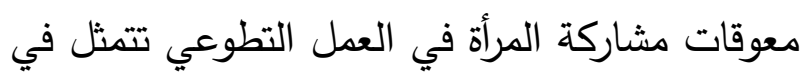
عدم وضوح مفهوم التطوع لدى المرأة.

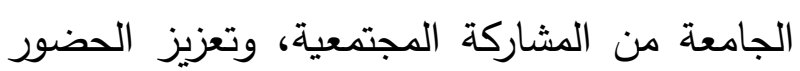
نتائج السؤال الثالث:

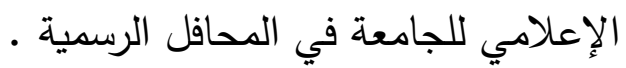
وتثير هذه النتيجة إلى اندماج الطالبات عينة البحث وينص السؤال الثالث على: "هل يختلف مستوى

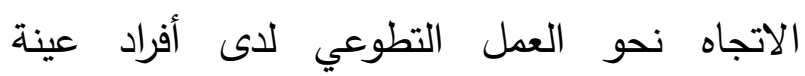

$$
\text { البحث؟". التجاه }
$$

للإجابة على هذا السؤال تم حساب المتوسطات الحسابية والانحرافات المعيارية لاستجابات أفراد

العينة على مقياس الاتجاه نحو العمل التطوعي ؛

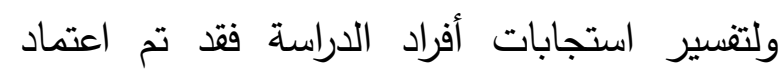
التدريج الخماسي الآتي:

1. عندما يكون المتوسط الحسابي للاستجابات [من 1 إلى 1,80] تعبر عن مستوى منخفض جدًا. 2. عندما يكون المتوسط الحسابي للاستجابات [1,82 إلى 2,61] تعبر عن مستوى منخفض. 3. عندما يكون المتوسط الحسابي للاستجابات [2,62 إلى 3,42] تعبر عن مستوى متوسط. 4. عندما يكون المتوسط الحسابي للاستجابات [3,43 إلى 4,28] تعبر عن مستوى مرتفع. 5. عندما يكون المتوسط الحسابي للاستجابات [5ن 4,29 إلى 5,00] تعبر عن مستوى مرتفع جدًا. والجدول (8) يوضح هذه النتائج.

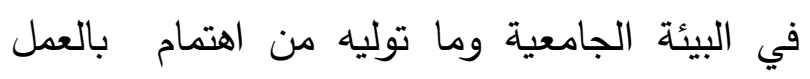

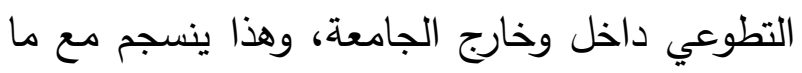
تمتاز به الاناث من قدرات وامكانات وطاقات وهات لهات لهات عاطفية يمكن استثمارها في العمل التطوعي، وتمثل

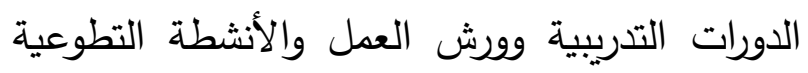
التي تقام من خلال المركز بالجامعة عامل دفع

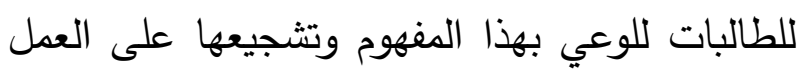
في هذا المجال وخاصة في إطار التحولات الجذرية التي يشهدها العالم في العقدين الأخيرين. وتختلف هذه النتيجة مع ما توصلت إليه دراسة الباز (2002) على طلاب المرحلة الجامعية في مدينة الرياض من قصور دور الجامعات في التوعية بأهمية العمل التطوعي. أو إلى افتقار التطوع أحيانًا لإدارة خاصة للمتطوعين، لتنسيق الجهود وتنظيمها،

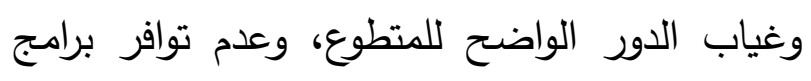
خاصة لتدريب المتطوعين (المرواني، 2012) ؛ وربما تفتقر الجامعة إلى العمل التطوعي المقصود الذي يرتكز على أسس وقواعد عامة. أو إلى عدم

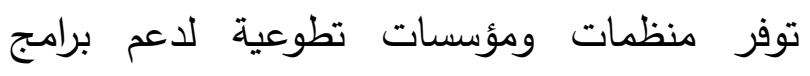
التطوع وتقديم التسهيلات اللازمة لها، (العوضي لنوعيل 
جدول (8) المتوسطات الحسابية والانحرافات المعيارية لاستجابات أفراد العينة حول مستوى الاتجاه نحو العمل التطوعي

\begin{tabular}{|c|c|c|c|c|}
\hline 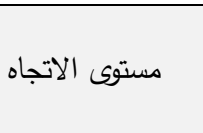 & المعياري & الحسابي & 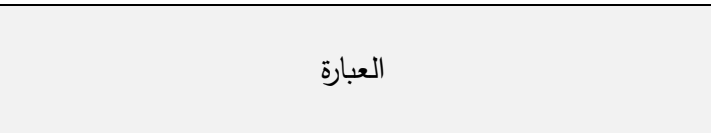 & s \\
\hline مرتفعة جدًا & .28 & 4.93 & العمل التطوعي يشعر المتطوع بالثقة بالنفس. & 1 \\
\hline مرتقعة جدًا & .45 & 4.77 & ينمي العمل التطوعي الثعور بالمسئولية الاجتماعية. & 2 \\
\hline مرتفعة جدًا & .46 & 4.81 & يحقق العمل التطوعي الشعور بالسعادة لدى المتطوع. & 3 \\
\hline مرتفعة جدًا & .52 & 4.81 & يسهم العمل التطوعي في صقل شخصية المتطوع. & 4 \\
\hline مرتفعة جدًا & .39 & 4.85 & ينمي العمل التطوعي الثعور بقيمة العمل التعاوني. & 5 \\
\hline مرتفعة جدًا & .46 & 4.80 & يحقق العمل التطوعي طموح المتطوع وأهدافه. & 6 \\
\hline مرتفعة جدًا & .56 & 4.73 & يسهم العمل التطوعي في الثعور بالأمن والأمان. & 7 \\
\hline مرتفعة جدًا & .54 & 4.74 & العمل التطوعي فرصة للتعبير عن الذات. & 8 \\
\hline مرتقعة جدًا & .81 & 4.46 & ينمي العمل التطوعي الوعي بقيمة العمل الجماعي. & 9 \\
\hline مرتفعة جدًا & .47 & 4.85 & ييرز العمل التطوعي الطاقة الايجابية للمتطوع. & 10 \\
\hline مرتفعة جدًا & .44 & 4.77 & ينمي العمل التطوعي روح الانتماء للوطن. & 11 \\
\hline مرتفعة جدًا & .83 & 4.39 & للتقدير . لـعل التطوعي بعض الحاجـات لدى المتطوع كالحاجـة & 12 \\
\hline مرتفعة جدًا & .74 & 4.57 & العمل التطوعي ينمي الاستقلالية لاى المنطوع. & 13 \\
\hline مرتنعة جدًا & .84 & 4.53 & العمل التطوعي وسيلة لشغل أوقات الفراغ بطريقة إيجابية. & 14 \\
\hline مرتفعة جدًا & .29 & 4.93 & يحقق العمل التطوعي المشاركة الوجدانية للآخرين. & 15 \\
\hline مرتفعة جدًا & .47 & 4.89 & \multicolumn{2}{|c|}{ المتوسط العام } \\
\hline
\end{tabular}

يتضح من جدول (8) أن مستوى الاتجاه نحو العمل وحجازي ومحمد (2011)؛ المغيضب وعثان التطوعي لدى أفراد عينة البحث جاءت مرتفعة جدًا. (2013)، والخدام (2013)، والألفي (2017) إلى وتدل هذه النتيجة على وجود حالة عالية من أن اتجاهات شباب الجامعة اتسمت بالايجابية بشكل الاستعدادات العقلية والنفسية والعصبية لدى أفراد عام. عينة البحث نحو العمل التطوعي. بمعنى أن لديهن بينما تختلف مع نتائج دراسات كل من: الباز درجة مرتفعة من العاطفة الايجابية التي لها أثر (2001)، والعنزي (2006)، وعارف (

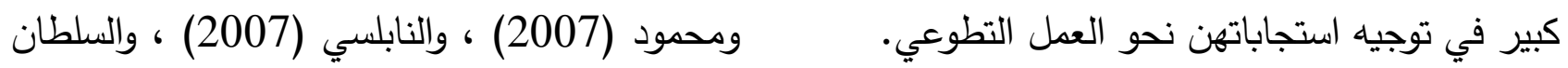
وتتقق هذه النتيجة مع نتائج دراسات كل من: (2009) ، والخدام (2013) إلى وجود اتجاهات Esmond (2001) ( المرزوقي (2009)؛ والمالكي (2010) ، و 
وينص السؤال الرابع على : " هل تختلف درجة استجابات أفراد عينة البحث في الدوافع نحو العمل

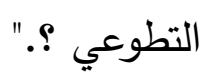

وللإجابة على هذا السؤال تم حساب المتوسطات الحسابية والانحرافات المعيارية لاستجابات أفراد

العينة على مقياس الاتجاه نحو العمل التطوعي ؛

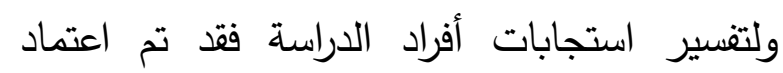
التدريج الخماسي السابق: والجدول (9) يوضح هذه
التطوعي. وضعف مشاركة وانخراط الشباب الجامعي في مجالات العمل التطوعي بشكل عام . ويمكن تنسير هذه النتيجة في إطار قيم المجتمع السعودي حيث يرى أصحاب النظرية الوظيفية البنائية في تفسيرها للاتجاه أن الاتجاه يرتبط بقيم المجتمع ووظيفيًا يعمل على التوافق مع واقع البيئة. وتشير هذه النتيجة إلى ايمان عينة البحث بأهمية هذا العمل النابع من الدين الاسلامي الحنيف الذي لهي

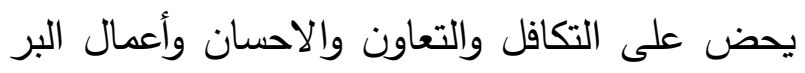
وتحمل المسئولية الاجتماعية تجاه أبناء المجتمع. نتائج السؤال الرابع: جدول (9) المتوسطات الحسابية والانحرافات المعيارية لاستجابات افراد العينة للاوافع نحو العمل التطوعي

\begin{tabular}{|c|c|c|c|c|}
\hline 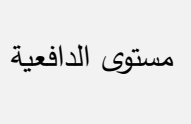 & الانحراف & المتوسط & 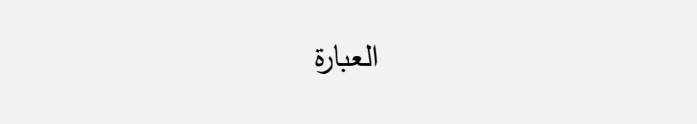 & r \\
\hline مرتقعة جدًا & .62 & 4.71 & حث الدين الاسلامي على الأعمال التطوعية. & 1 \\
\hline مرتفعة جدًا & .48 & 4.79 & الرغبة في التعلم واكتساب الخبرات والمهارات جديدة. & 2 \\
\hline مرتفعة جدًا & .36 & 4.92 & تحستـين العلاقـات الاجتماعيـة بـين الطبقـات المختلفــة فـي & 3 \\
\hline مرتقعة جدًا & .53 & 4.75 & شغل أوقات الفراغ بما يفيد. & 4 \\
\hline مرتفعة جدًا & .39 & 4.89 & شعور الفرد بأنه عضو فعال في المجتمع. & 5 \\
\hline 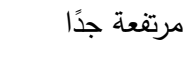 & .72 & 4.52 & الاحساس بالمسئولية الاجتماعية. & 6 \\
\hline مرتقعة جدًا & .65 & 4.63 & كسب تقدير واحترام الذات. & 7 \\
\hline مرتفعة جدًا & .64 & 4.65 & تكوين علاقات اجتماعية مع الآخرين. & 8 \\
\hline مرتفعة جدًا & .52 & 4.79 & الرغبة في كسب الاحترام والتقدير من الآخرين. & 9 \\
\hline مرتقعة جدًا & .41 & 4.90 & الشعور بالرضا عن النفس. & 10 \\
\hline مرتقعة جدًا & .75 & 4.67 & أهمية خلق الايثار بالنسبة للمسلم. & 11 \\
\hline مرتقعة جدًا & .97 & 4.41 & حل المشاكل والمعضلات وخاصة وقت الازمات. & 12 \\
\hline مرتقعة جدًا & .64 & 4.79 & 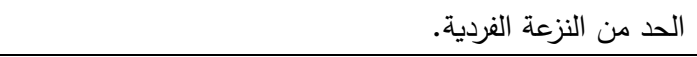 & 13 \\
\hline مرتفعة جدًا & .43 & 4.86 & تقوية الانتماء الوطني. & 14 \\
\hline مرتقعة جدًا & .64 & 4.91 & \multicolumn{2}{|c|}{ المتوسط العام } \\
\hline
\end{tabular}


عن وجود عوامل داخلية وخارجية تتعلق بالحافزية

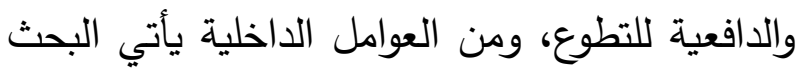
عن الأنشطة والمتعة والفرص المختلفة، الحاجة إلى وملى لئل الثعور بالرضا عن الذات، والحاجة إلى التفاعل

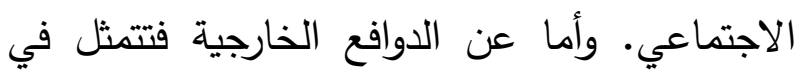
الرغبة في الإنتاج، الحاجة إلى التعزيز اللفظي Fitch والمعنوي بأشكاله المختلفة. ونظرية فيتش الإنى التي أشار فيها إلى ثلاث فئات من الدوافع: حب الخير، إرضاء الأنا، والتفاعل الاجتماعي. وعن دافع

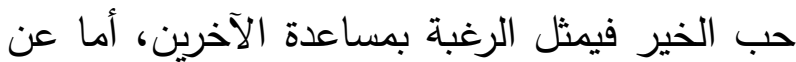
إرضاء الأنا فمن خلال زيادة المهارات، والمعرفة، واحترام الذات، وأما عن الدوافع الاجتماعية فتعبر عن البحث عن الانتماءات الاجتماعية والأنشطة .(Utah Arts Council Publication, 2006)

$$
\text { في (عيد، 2009) }
$$

ويمكن أن تفسر هذه النتيجة بوجود الدوافع الذاتية لاى أفراد العينة والتي ت تعكس اهتماماتهن واحتياجاتهن للتحول من الفردية والمصلحة الخاصة إلى المصلحة العامة والرغبة في العمل التطوعي، ولاكتساب خبرة لها معنى لتحقيق الأهداف الذاتية . نتائج السؤال الخامس: وينص السؤال الخامس على : " هل تختلف درجة استجابات أفراد عينة البحث في المشاركة في العمل

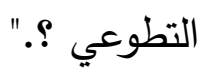
للإجابة على هذا السؤال تم حساب المتوسطات الحسابية والاتحرافات المعيارية لاستجابات أفراد
يتضح من جدول (9) أن الدوافع نحو العمل التطوعي لدى أفراد العينة جاءت مرتفعة جدًا. ويدل ذلك على تعدد الدوافع والأسباب لديهن للانضمام للعمل التطوعي وهذا دليل على أنه ليس بالضرورة

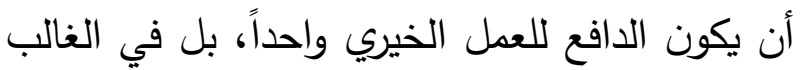

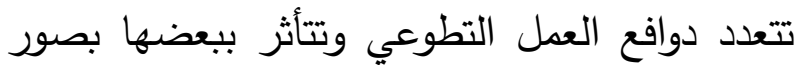
متفاوتة كما في دراسة الباز (2002)، ودراسة المحاميد (2001). وتتسق هذه النتيجة مع ما أثارت إليه نتائج الدراسة التي أصدرتها الهيئة العامة للإحصاء (GaStats)

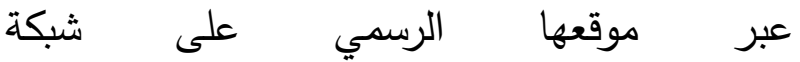
الإنترنت $\quad$ www.stats.gov.sa 2019م والذي أجريت للمرة الأولى على مستوى المملكة ضمن متطلبات رؤية 2030، إلى تعدد دوافع العمل التطوعي لدى السعوديين حيث يرى (40.6\%) من إجمالي المتطوعين السعوديين (ذكور وإناث) بأنَّ حب مساعدة الآخرين هو الدافع وراء القيام بأعمال التطوع، بينما (28,7 \% ) يرون التطوع واجب وطني، و (8.5 \%) من المتطوعين السعوديين يرون في المشاركة بأعمال التطوع فرصة جيدة للتواصل، و (4.3 \%) يرون بأنَّ أعمال التطوع تساهم في ت تطوير المهارات https://www.stats.gov.sa / ar/ news/325 وتأتي هذه النتيجة أيضًا متسقة مع تفسيرات العديد من النظريات التي فسرت دوافع ومحفزات التطوع منها نظرية كيد J. R. Kidd، والتي تحدث فيها 
العينة على مقياس الاتجاه نحو العمل التطوعي؛ التدريج الخماسي السابق، والجدول (10) يوضح ولتفسير استجابات أفراد الدراسة فقد تم التهاه التماد جدول (10) المتوسطات الحسابية والانحرافات المعيارية لاستجابات افراد العينة حول المشاركة في العمل التطوعي

\begin{tabular}{|c|c|c|c|c|}
\hline 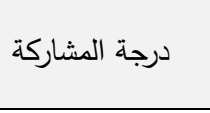 & الالتحراف & الحسابي & 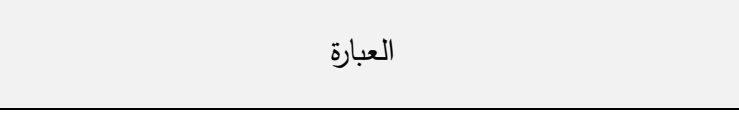 & s \\
\hline منخفضة جدًا & .78 & 1.47 & أشارك في الأعمال التطوعية بدار الأيتام. & 1 \\
\hline منخفضة جدًا & .62 & 1.29 & أشارك في الأعمال التطوعية بدار المسنين. & 2 \\
\hline منخفضة جدًا & .49 & 1.21 & أشارك في الأعمال التطوعية بجمعيات الإغاثة. & 3 \\
\hline منخفضة & 1.27 & 1.93 & أشارك في رعاية ذوي الاحتياجات الخاصة. & 4 \\
\hline منخفضة جدًا & .45 & 1.19 & أقدم مساعدات في فصول محو الأمية. & 5 \\
\hline منخفضة جدًا & .49 & 1.21 & أسهم في رعاية الأرامل ماديا. & 6 \\
\hline 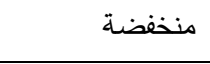 & 1.04 & 1.89 & أسهم في رعاية الأسر الفقيرة. & 7 \\
\hline منخفضة جدًا & .35 & 1.07 & أشارك في تقديم المساعدة للمدمنات. & 8 \\
\hline منخفضة جدًا & .57 & 1.23 & أشارك في إقامة ندوات لنشر ثقافة العمل التطوعي. & 9 \\
\hline منخفضة & .82 & 1.87 & أثشارك في إقامة المعارض للجمعيات التطوعية. & 10 \\
\hline منخفضة & .77 & 1.92 & أشارك في الأنشطة الصيفية التي تقيمها الجمعيات التطوعية. & 11 \\
\hline منخفضة جدًا & .71 & 1.33 & أشارك في الإعداد وتقديم دورات تدريبية تابعة للجمعيات التطوعية. & 12 \\
\hline 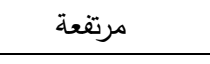 & 1.71 & 3.55 & أتبرع بالدم لإنقاذ حياة أي شخص. & 13 \\
\hline متوسطة & 1.62 & 2.89 & أشارك في إقامة ندوات لنشر الثقافة الصحية. & 14 \\
\hline 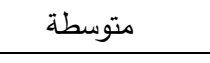 & 1.53 & 2.94 & أميل إلى العمل في فريق ينسق التبرعات لتوزيعها. & 15 \\
\hline متوسطة & 1.47 & 2.95 & أشارك في الأعمال التطوعية التي تقدها الجامعة. & 16 \\
\hline منخفضة & .76 & 1.96 & \multicolumn{2}{|c|}{ المتوسط العام } \\
\hline
\end{tabular}

يتضح من الجدول (10) اختلاف درجة استجابات وتتسق هذه النتيجة مع ما توصلت إليه دراسة الثبكة

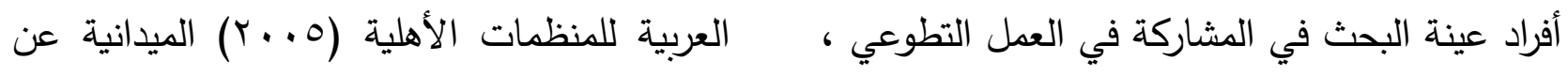

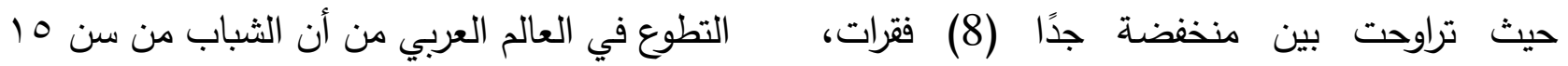
ومنخفضة (4) فقرات، ومتوسطة (3) فقرات، حتى ·r سنة هم أقل فئة مهتمة بالتطوع برغم

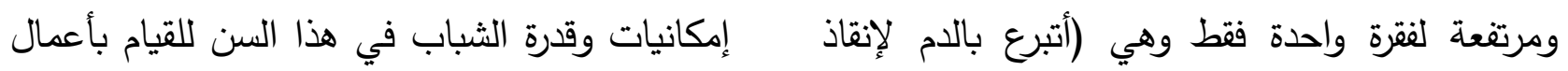

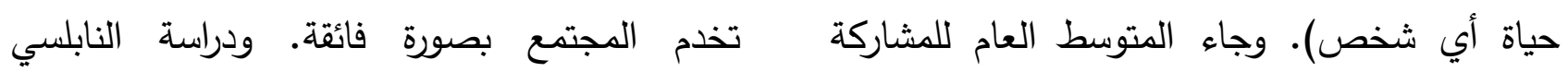
بدرجة منخفضة. (2007) التي توصلت إلى ضعف مشاركة الثباب الجامعي في العمل التطوعي. 
القيادية، ولد أوضحت دراسة حديثة للشبكة العربّة للمنظمات الأهلية أن هنان انحسارا للتطوع بين النساء كاتجاه عام، وقد حدث ذلك بسبب ضغوط

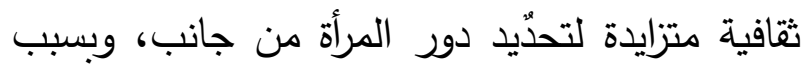
ضغوط اقتصادية من جانب آخر، أدت إلى انشغال

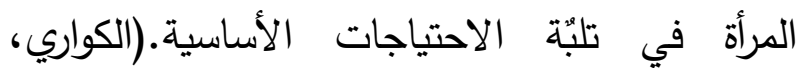
( 2004 وقد تفسر هذه النتيجة على ضوء ما ذكره ملاوي (2008: 256) من أن ضعف مساهمة النساء والفتيات في العمل التطوعي، ربما يعود إلى تأثير منظومة القيم الاجتماعية التي تحد من المشاركة

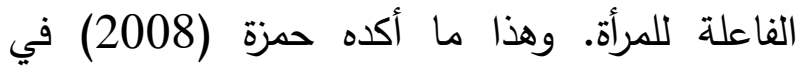
دراسته من أن أهم العوامل التي تحد من مشاركة المرأة في العمل التطوعي هو الموروث الاجتماعي الذي يشجع بقاء المرأة في المنزل، وعدم التقدير

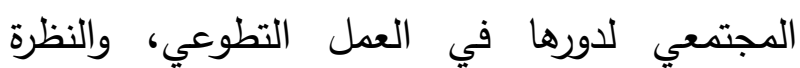

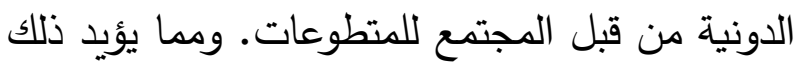
ما توصل إليه أقطم (2014) من أن المعوقات التي

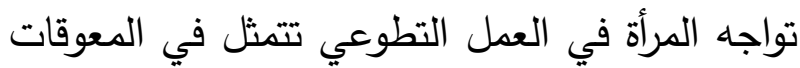
الاجتماعية والثقافية والمادبة والسياسية ، والمعقات التنظيمية والادارية والمعوقات الثخصية.

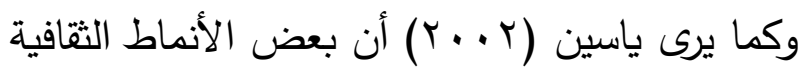
السائدة في المجتمع تسهم في تقليص مشاركة

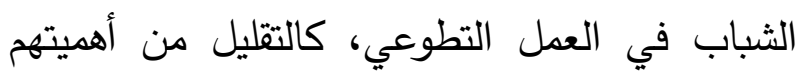
الاجتماعية ومن دورهم في بناء المجتمع، وكذلك الكي

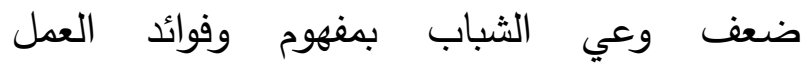
التطوعي.كما أن هنالك أسباب تتحمل مسئوليتها المؤسسات الحكومية والأهلية تتمثل في قلة التعريف
ودراسة حجازي ومحمد (2011) التي أشارت إلى وجود اتجاهات سالبة للفتاة الجامعية نحو المشاركة

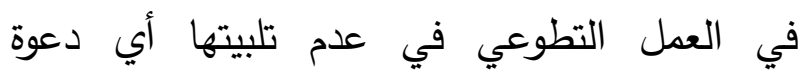
للمشاركة في العمل التطوعي وضعف مبادرتها للقيام

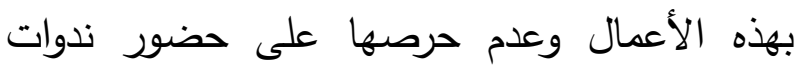
تحث على العمل التطوعي، وعدم تشجيع زميلاتها للانضمام للعمل التطوعي. ودراسة الهيئة العامة

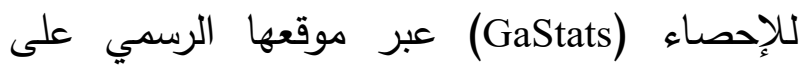
شبكة الإنترنت www.stats.gov.sa في 21 يونيو 2019م التي توصلت إلى أن نسبة إجمالي

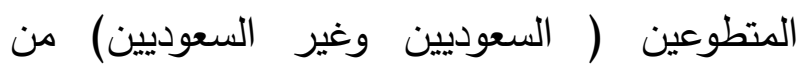
إجمالي عدد سكان المملكة لَّن أعمارهم 15 سنة فأكثر قد بلغت خلال الاثثي عشر شهراً السابقة للمسح (14.7\%) فيما بلغت نسبة المتطوعين السعوديين (الذكور والإناث) للسكان السعوديين لمن لفن أعمارهم 15 سنة فأكثر خلال الاثني عشر شهراً السابقة للمسح (16.8\%)، وبلغت نسبة المتطوعين السعوديين الذكور إلى إجمالي السعوديين الذكور

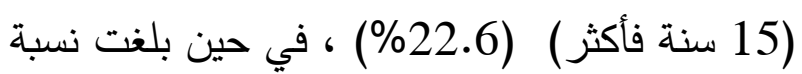
المتطوعات السعوديات إلى إجمالي السعوديات (15)

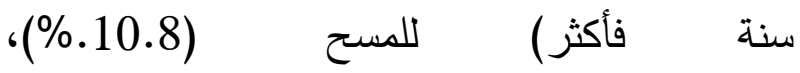
https://www.stats.gov.sa/ar/news/325 كما تتسق هذه النتيجة مع ما أشارت إليه البيانات

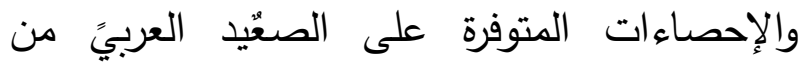

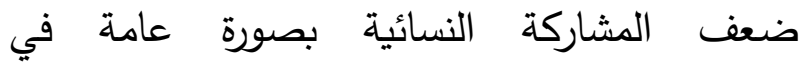
التنظيُمات والجمعُيات الأهلية، وحتى في الحالات

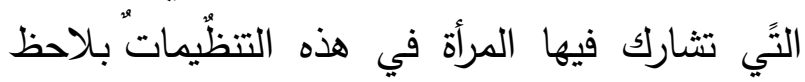
اقتصار وجودها على المستويّات القاعدية دون 
بالبرامج والنشاطات التطوعية أو عدم السماح والمشاركة فيه لدى أفراد عينة البحث وفقاً للسنة للشباب بالمشاركة في صنع القرار داخل المؤسسة الدراسية (التحضرية / الرابعة)؟".

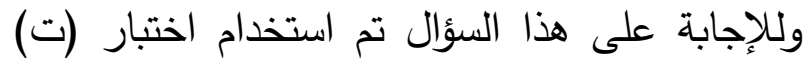
وقلة تشجيع ودعم العمل التطوعي

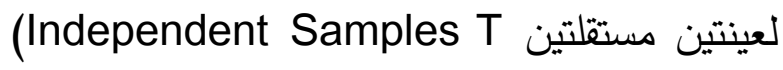

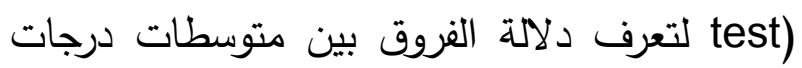

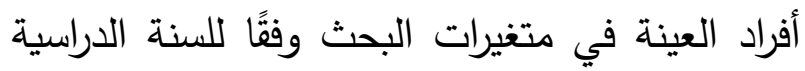
(التحضرية/الرابعة). والجدول (11) يوضئح بينما تختلف هذه النتيجة مع نتائج دراسة العوضي لفئي (2013) حيث وجد أن مشاركة أفراد عينة الدراسة

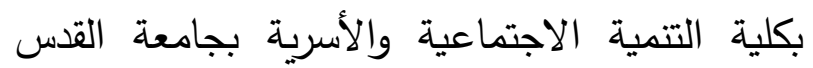
المفتوحة كان ذا تقدير مرتفع.

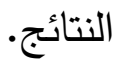
السؤال السادس: وينص السؤال السادس على: " هل تتباين درجة الوعي بمفهوم العمل التطوعي والاتجاه نحوه ودوافعه جدول (11) نتائج اختبار ت لالالة الفروق في درجة الوعي بمفهوم العمل التطوعي والاتجاه نحوه ودوافعها والمشاركة فيه لایى أفراد عينة البحث وفقاً للسنة الدراسية (التحضرية / الرابعة)

\begin{tabular}{|c|c|c|c|c|c|c|c|}
\hline مستوى الدلالة & قيمة (ت) & درجات & الانحراف المعياري & المتوسط الحسابي & العدد ال العد & السنة الدراسية & المتغير \\
\hline \multirow[t]{2}{*}{.92} & \multirow[t]{2}{*}{.36} & \multirow[t]{2}{*}{148} & 70.56 & 5.50 & 68 & التحضرية & \multirow{2}{*}{ الوعي بمفهوم العمل } \\
\hline & & & 71.33 & 4.80 & 82 & الرابعة & \\
\hline \multirow{2}{*}{1.29} & \multirow{2}{*}{.19} & \multirow{2}{*}{148} & 71.50 & 4.30 & 68 & التحضرية & \multirow{2}{*}{ الاتجاه نحو العمل } \\
\hline & & & 70.21 & 7.28 & 82 & الرابعة & \\
\hline \multirow{2}{*}{.92} & \multirow{2}{*}{.36} & \multirow{2}{*}{148} & 70.56 & 5.50 & 68 & التحضرية & \multirow{2}{*}{ التطوعي العمل } \\
\hline & & & 71.33 & 4.80 & 82 & الرابعة & \\
\hline \multirow{2}{*}{.23} & \multirow{2}{*}{.82} & \multirow{2}{*}{148} & 31.81 & 8.22 & 68 & التحضرية & \multirow{2}{*}{ المشاركة في العمل } \\
\hline & & & 32.16 & 9.96 & 82 & الرابعة & \\
\hline
\end{tabular}

وتتفق هذه النتيجة مع نتيجة دراسة الخدام (2013)

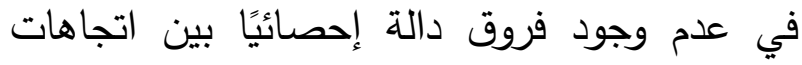

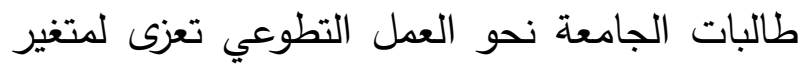
المستوى الدراسي. كما تتفق مع دراسة إبراهيم
يتضح من الجدول (11) عدم وجود فروق دالة إحصائيًا في متغيرات: مفهوم العمل التطوعي والاتجاه نحوه ودوافعه والمشاركة فيه لاى أفراد عينة البحث وفقاً للسنة الدراسية (التحضرية / الرابعة). 
وسليمون (2017) التي توصلت لعدم وجود فروق وينص السؤال السابع على : " هل تتباين درجة

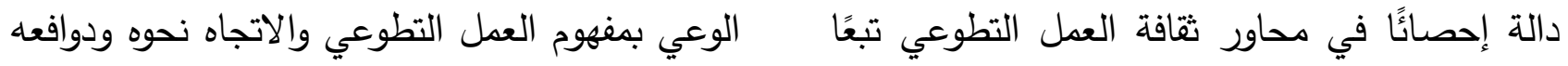

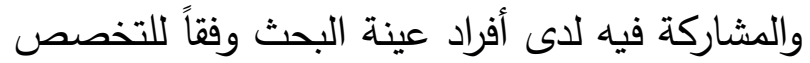
لمتغير السنة الدراسية.

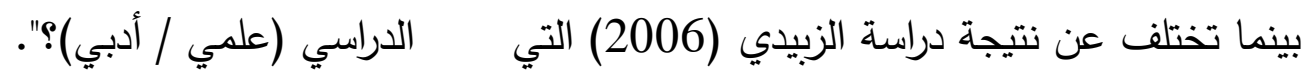
للإجابة على السؤال السابع تم استخدام اختبار (ت) لإبي (ت) بينت وجود فروق دالة إحصائيًا بين اتجاهات طلبة لئيا الجامعة نحو العمل التطوعي تعزى لمتغير المستوى

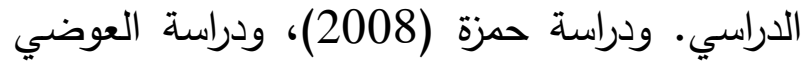

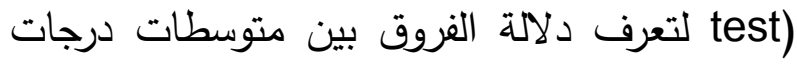
(2013) التي أظهرتا وجود فروق دالة إحصائياً في

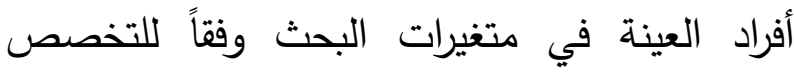

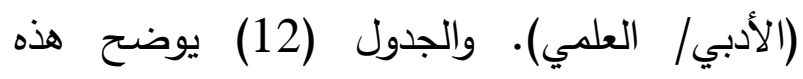
مستوى ثقافة الشباب الجامعي نحو المشاركة بالعمل التطوعي تبعا لمتغير العمر لصالح صغار السن ل (أقل من 30 سنة) .

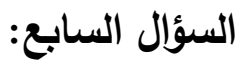
جدول (12) نتائج اختبار ت لدلالة الفروق في درجة الوعي الوعي بمفهوم العمل التطوعي والاتجاه نحوه ودوافعه والمشاركة

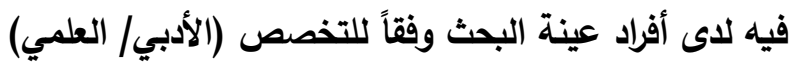

\begin{tabular}{|c|c|c|c|c|c|c|c|}
\hline مستوى الدلالة & قيمة (ت) & الحرية & الانحراف المعياري & المتوسط الحسابي & العدد & التخصص & المتغير \\
\hline \multirow{2}{*}{1.22} & \multirow[t]{2}{*}{.23} & \multirow[t]{2}{*}{80} & 34.85 & 8.68 & 39 & الأدبي & \multirow{2}{*}{ العمل التطوعي بمفهوم } \\
\hline & & & 32.32 & 9.89 & 43 & العلمي & \\
\hline \multirow{2}{*}{1.02} & \multirow{2}{*}{.31} & \multirow[t]{2}{*}{80} & 70.18 & 6.93 & 39 & الأدبي & \multirow{2}{*}{ الاتجاه نحو العمل } \\
\hline & & & 71.47 & 4.28 & 43 & العلمي & \\
\hline \multirow{2}{*}{.103} & \multirow{2}{*}{.92} & \multirow{2}{*}{80} & 71.00 & 4.95 & 39 & الأدبي & \multirow{2}{*}{ التطوعي العمل } \\
\hline & & & 71.12 & 5.20 & 43 & العلمي & \\
\hline \multirow{2}{*}{1.22} & \multirow{2}{*}{.23} & \multirow{2}{*}{80} & 34.85 & 8.68 & 39 & الأدبي & \multirow{2}{*}{ المشاركة في العمل } \\
\hline & & & 32.32 & 9.89 & 43 & العلمي & \\
\hline
\end{tabular}

يتضح من الجدول (12) عدم وجود فروق دالة والاتجاه نحوه ودوافعه والمشاركة فيه لدى أفراد عينة

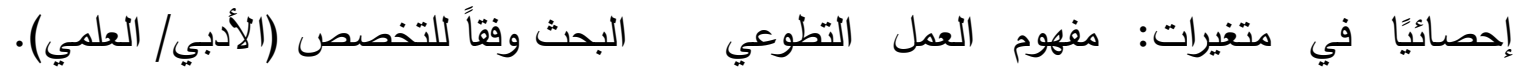


وتتفق هذه النتيجة جزئيًا مع نتيجة دراسة العقيل العلوم الإنسانية اختلافات كبيرة عن طلاب (1423) التي بينت عدم وجود فروق واضحة بين التخصصات الأخرى. مستوى الاتجاه نحو العمل الدعوي كأحد أنواع العمل ويمكن تفسير نتيجتي السؤالين السادس والسابع

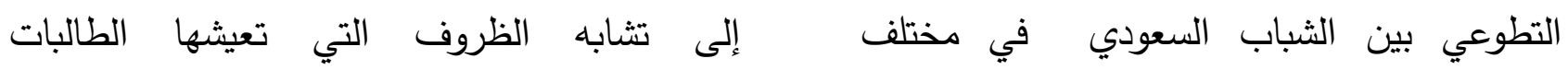

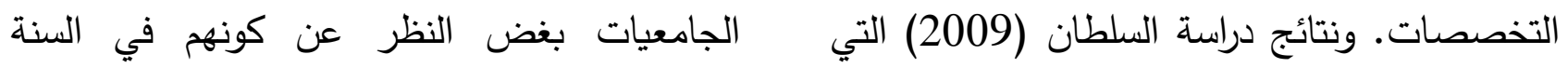
التحضيرية أو الرابعة أو التخصص الفصل العلمي أو أظهرت عدم وجود فروق ذات دلالة إحصائية بين اتجاهات الثباب الجامعي من جامعة الملك سعود الأدبي فالجميع يعيش في بيئة واحدة بظروف حياتية

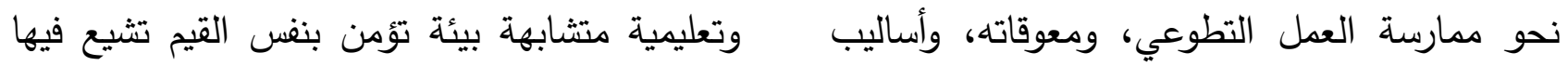
فعاليته، تعزى إلى اختلاف الكلية. وهذا يعني أن ثقافة العمل التطوعي بنسبة لا بأس بها. الطلاب لديهم اتجاهات متشابهة نحو ممارسة العمل توصيات البحث:

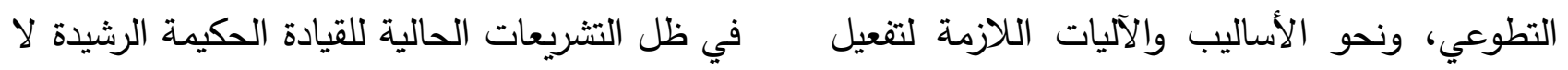
مشاركتهم في العمل التطوعي. كما تتفق جزئيا مع بد أن تلعب الجامعات السعودية دوراً رئيساً في تتمية المسئولية الاجتماعية لاى الثباب السعودي بتفعيل الوظيفة الثالثة للجامعات - خدمة المجتمع - التي تقدمها الجامعة كأفضل معيار للحكم على مدي كفاءتها في تنمية المجتمع. وذلك من خلال: 1. عمل شراكات بين الجامعة والمؤسسات الخيرية

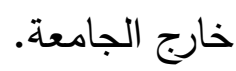
2. تخصيص مشروع لخدمة المجتمع ضمن لمن

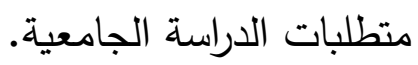

3. تضمين مشروع تثقيف طلبة الجامعة بالعمل الخيري ضمن برامج الأنشطة بالجامعة.

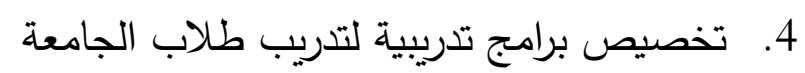

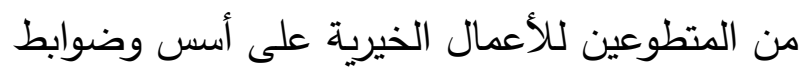
نتائج دراسة عبد العزيز (2019) التي أوضحت عدم وجود فروق دالة احصائيا بين متوسطات درجات عينة الدراسة فيما يتعلق بأبعاد مقياس الاتجاهات نحو المشاركة في العمل التطوعي. وتختلف هذه النتيجة مع نتيجة دراسة رضا (2006) التي توصلت إلى وجود فروق دالة إحصائيًا في

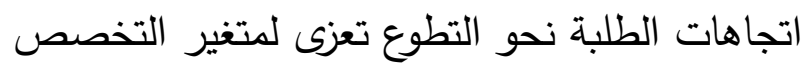
لصالح طلبة الخدمة الاجتماعية. ونتيجة دراسة السلطان (2009) التي أظهرت فروق جوهرية ذات الاته دلالة إحصائية بين اتجاهات الثباب الجامعي من جامعة الملك سعود نحو محوري مجالات العمل

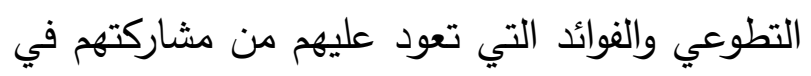
العمل التطوعي تعزى إلى اختلاف تخصصاتهم. العمل الخيري.

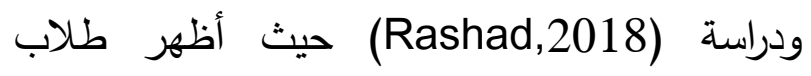


- أقطم، حسن فخري ابراهيم (2014). معوقات مشاركة المرأة في العمل التطوعي من وجهة نظر التراهر المتطوعين والعاملين في مؤسسات المجتمع المدني في محافظة نابلس ، رسالة ماجستير غير منشورة ، كلية الدراسات العليا ، جامعة النجاح الوطنية . - الباز، راشد سعد (2002). الثباب والععل التطوعي : دراسة ميدانية علي طلاب المرحلة الجامعية في مدينة الرياض ، مجلة البحوث الأمنية، ، . $117-58$ 10 (10)20

- برقاوي ، خالد يوسف ( 2008) : اتجاهات الثباب السعودي نحو العمل التطوعي. مجلة جامعة الملك عبد العزيز الآداب والمعلوم الإنسانية ، لهمبل $.131-65$ ، (2)16 - برو، باسل (2015)، اتجاهات الثباب الجامعي نحو العمل النطوعي (دراسة ميدانية). رسالة ماجستير غير منشورة، كمية الآداب، جامعة دمشق. - حجازي، نادية عبد العزيز محمد، ومحمد ،إيمان محمد إلياس (2011): اتجاهات الفتاة الجامعية نحو العمل التطوعي في المجتمع السعودي ودور الخدمة الاجتماعية في تتميتها: دراسة ميدانية مطبقة على طالبات كليات جامعة الملك عبد العزيز وجامعة أم القرى. مجلة دراسات في الخدمة الاجتماعية والعلوم الإنسانية ، مصر ، 30(9) ، 4109 - 4192. - الحربي، عبد الغني محمد (2014). دور الأسرة في تنشئة الأبناء على العمل التطوعي: دراسة

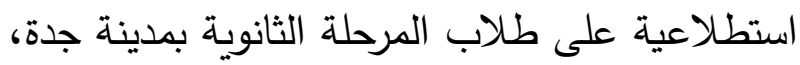

5. تضمين البرنامج الأكاديمي للطالب الجامعي

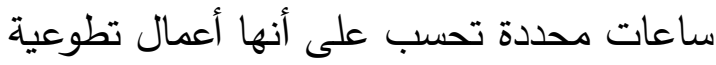
للمجتمع. 6. التسيق مع الوحدات والأقسام الأكاديمية لتشجيع برامج العمل التطوعي. 7. العمل على نشر ثقافة العمل التطوعي بدءا من لن

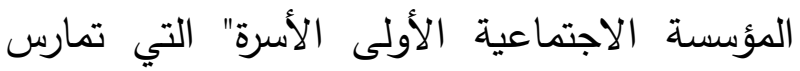

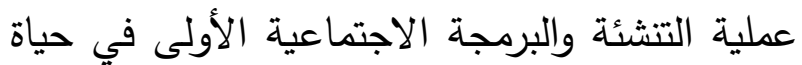
النشء - التي يفوق تأثيرها أثر أي مؤسسة اجتماعية أخرى لكونها تقوم على إثباع حاجات الأبناء الفسيولوجية والعقلية المعرفية والعاطفية بالإضافة إلى غرس أساليب التعامل الاجتماعي ومعايير السلوك بما يكفل لهم القيام بأدوارهم الحياتية، وصولا إلى جميع مؤسسات المجتمع لهيل الرسمية منها وغير الرسمية.

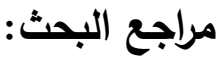
- إبراهيم ، حكمت علي (2006) • دراسة تحليلية للعوامل الاجتماعية المؤدية لمشاركة الثباب الجامعي في المشروعات التطوعية بجامعات أندية التطوع. رسالة ماجستير غير منشوقة ، كلية الخدمة الاجتماعية ، جامعة حلوان • - إبراهيم، هيام نسيم وسليمون، ريم (2017). مستوى ثقافة العمل التطوعي لدى طلبة جامعة دمثق في ظل الأزمة السورية. مجلة جامعة البيت، المجلد 39 (37)، 111 - 165. 
أبو زيلد، صافيناز محمد (2020). معوقات مشاركة

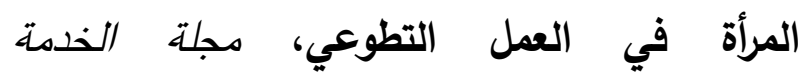
الاجتماعية، الجمعية المصرية للأخصائيين الإجتماعيين، 63(2)، 15 - 42. - السلطان ، فهر سلطان (2009). اتجاهات الثباب الجامعي الذكور نحو العمل التطوعي دراسة تطبيقية على جامعة الملك سعود، مجلة رسالة الجئي الخليج العربي، (112)، 73 - 127. - الثامي، أروى عبد العزيز (12020). دوافع العمل التعل

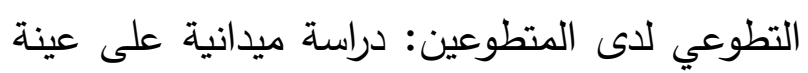

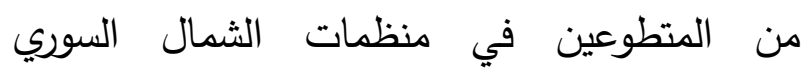
المحرر، مجلة ريحان للنشر العلدي، مركز فكر فئن

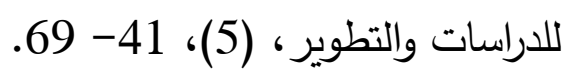

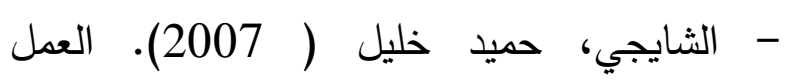
التطوعي أهميته معوقاته وعوامل نجاحه. ورقة عمل، حمئ، جامعة الرياض، سبتمبر ،المملكة العربية السعودية . https://ae.linkedin.com > pulse - الثبكة العربية للمنظمات الأهلية (2005). التطوع والمتطوعون في العالم العربي . - الثبيكي، الجازي محمد فها (1992). الجهود الإنسانية التطوعية في مجالات الرعاية الاجتماعية

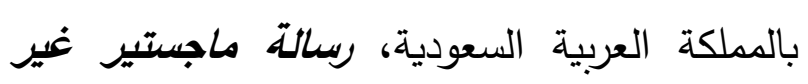
منشورة ، جامعة الملك سعود .الرياض. لمعند - الثناوي، أحمد محمد سيد (2010). مستوى (لقدئ ثقافة العمل التطوعي لدى الطلاب: دراسة ميدانية، مجلة كلية التربية بالاسماعيلية، (18)، 1 - 54.
مجلة العلوم الاجتماعية، الجمعية المصرية للاخصائيين الاجتماعيين، 52، 383 - 320.

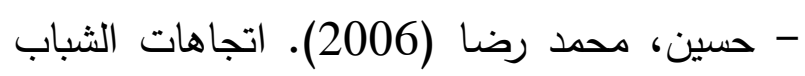
الجامعي نحو التطوع دراسة مطبقة على طلاب وطالبات جامعة السلطان قابوس. المؤتمر العلمي السابع عشر: الخدمة الاجتماعية وقضايا المرأة، المان. القاهرة، مصر • - حمزة، أحمد (2008). مؤشرات تخطيطية لتنشيط مشاركة المرأة في العمل التطوعي، المؤتمر العلمي الدولي الحادي والعشرون للخدمة الاجتماعية، جامعة حلوان، القاهرة، ص ص 3770 - 3830.

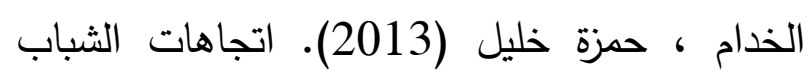
الجامعي نحو العمل التطوعي : كلية عجلون الجامعية نموذجاً، مجلة جامعة القدس الدفتوحة للأبحاث والدراسات ، (31) ، 219 - 246. - خليل ، هيام شاكر (2001): المشاركة في جماعات التطوع وتتمية المسئولية الاجتماعية. المؤتمر العلمي الرابع عشر ، الخدمة الاجتماعية بين الجهود التطوعية والاحتراف المهني ، كلية الخدمة الاجتماعية ، جامعة حلوان المجلد الثالث.

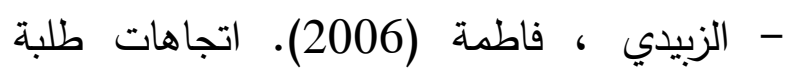

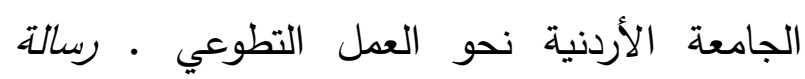

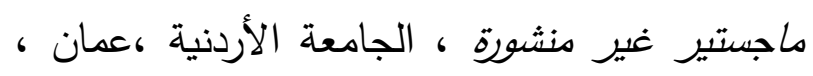
الأردن.

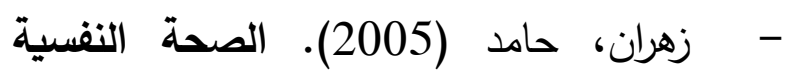
والعلاج النفسي. ط4، القاهرة: عالم الكتب. 
- العقيل، سليمان عبدالله (1423). الثباب السعودي والعمل الدعوى ,دراسة في استطلاع آراء الثباب السعودي حول العمل الدعوى التطوعي، مجلة جامعة الإمام محدد بن سعود الإسلامية، 40 .558- 500 ، (1)

- عنان ، محمد رضا حسين (2006) : اتجاهات

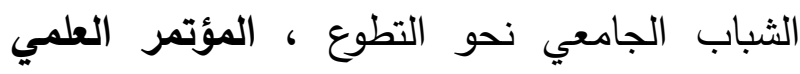

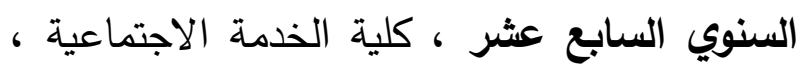

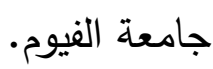
- العنزي، موضي (2006). أثر بعض المضوم المتغيرات

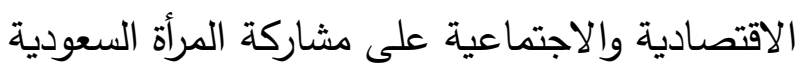
في الأعمال التطوعية، رسالة ماجستير غير منشورة ، المبنه

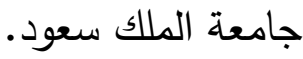
- عودة، نصر الدين (2017). المعوقات التي تعترض مشاركة الثباب الجامعي في العمل

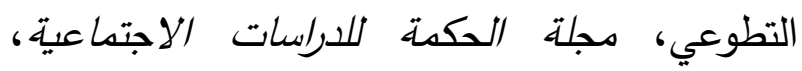
الجزائر ، 10، 155 - 154 - عوضي ، رأفت (2013). دور المؤسسات التعليمية في تعميم ثقافة المشاركة بالعمل التطوعي روفي من وجهة نظر الطلبة دراسة ميدانية كلية التنمية الادجتماعية والأسرة بجامعة القدس المفتوحة نموذجًا

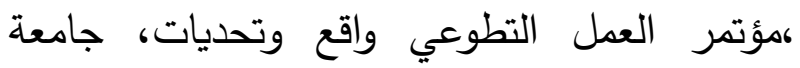
القدس المفتوحة ، 92 - 129. - عيد، أسماء شرباتي (2009). الدوافع الثخصية وراء العمل التطوعي بين المتوقع والواقع، المركز الفلسطيني للارشاد /www.pcc-jer.org/ar.
- الثهراني، عبد الله فلاح (2017). دور الجامعة

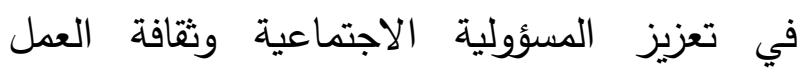
التطوعي: دراسة ميدانية على طلاب وطالبات الدبلوم العام في التربية في جامعة بيشة، مجلة كلية التربية، جامعة بنها،28(110)، 1 - 52. - عارف ، إيمان محمد (2002). دور الجامعة في تتمية اتجاهات الطلاب نحو العمل التطوعي في ضوء مفهوم التتمية المستدامة ، المؤتمر القومي السنوي العاشر ، جامعة المستقبل في الوطن العربي - مصر ، 2، 501 - 545. - عبد التواب ، هناء ربيع (2006). نحو إطار

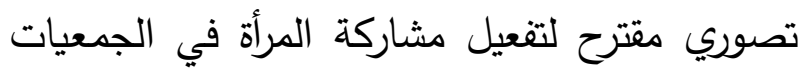

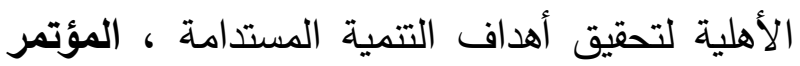
العلمي السنوي السابع عشر، كلية خدمة المجتمع ، الهميه

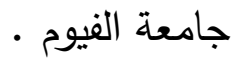
- عبد الحميد، أسماء عبد الفتاح نصر (2017). تصور مقترح لتنمية ثقافة العمل التطوعي في مصر في ضوء بعض الاتجاهات العالمية المعاصرة. دراسات عربية في التربية وعلم النفس. 86، 405 -

- عبد العزيز، أحمد علاء الدين (2019).

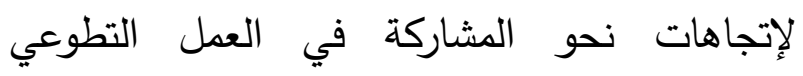
وعلاقتها بتحقيق الذات لدى عينة من الشباب الجامعي، رسالة ماجستير غير منشورة ، كلية التربية، جامعة عين شمس. 
- القريشي، عائدة مهدي (2018). الثباب والعمل السعودي: دراسة ميدانية، رسالة ماجستير غير

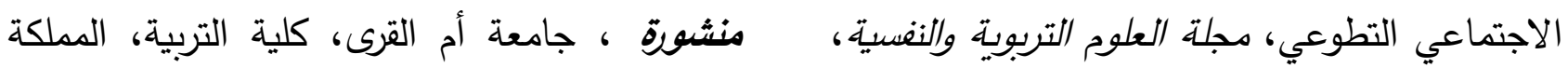

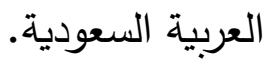

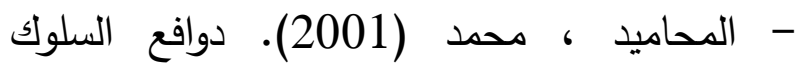

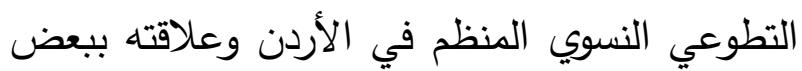
المتغيرات الاجتماعية والاقتصادية والتعليمية. رسالة ماجستير غير منثورة ، الجامعة الأردنية ، عمان ،

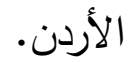
- محمود ،منال طلعت (2007): العمل التطوعي وتتمية ثثافة المواطنة، دراسة مطبقة علي أندية التطوع بمراكز الثباب بمحافظة الإسكندرية، مجلة

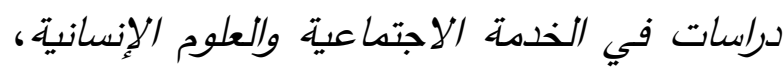
كلية الخدمة الاجتماعية، جامعة حلوان.23 (3 ) ، $.1447-1377$

- مرواني، حمد محمد ( 2012). دراسة في العمل الجماهيري التطوعي. المدينة المنورة، جامعة طيبة، منشورات كلية التربية. - المغيصب، عبد العزيز وعثمان، عبد الرحمن (1992). الثباب والعمل الاجتماعي التطوعي، دراسة للاتجاهات النفسية لدى عينة من طلبة جامعة قطر ، مجلة شؤون عربية، 40 (10)، 41 - 60. - مقدم، زينب ومحمداتتي، شهرزاد (2020). العمل مله التطوعي النسوي: الدوافع والمعيقات: دراسة ميدانية

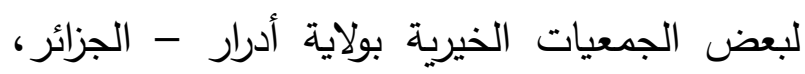
مجلة الجامعة الاسلامية لبحوث الانسانية، الجامعة الاسلامية بغزة، 28(1)، 233 - 209.

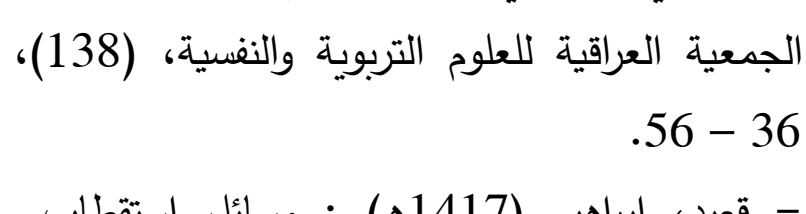

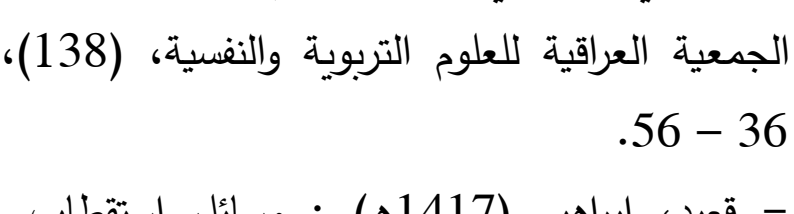
- قعيد، إبراهيم (1417هـ) : وسائل استقطاب المتطوعين والاستفادة من جهودهم ـ المؤتمر العلمي عن الخدمات التطوعية بالمملكة العربية السعودية، جامعة أم القرى، مكة المكرمة. - كريب، إيان (2004). النظرية الاجتماعية من من ماره بارسونز إلى هابرماس، ترجمة محمد حسين غلوم،

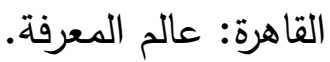
- الكندري، جاسم علي (2016). ثقافة العمل التطوعي لدى طلبة كلية التربية الأساسية بدولة

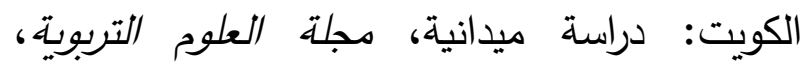
. 188 - 157 (1)، 157 - كواري ، عابشة (12006). دور المرأة في الهيئات (المانحة والمستُّدة) ، مؤتمر الإعلاميات العربيّات

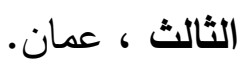
- المالكي ، سمر محمد غرم الله (2010.). مدي إدراك طالبات الدراسات العليا بجامعة أم القرى

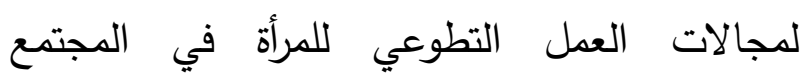
السعودي ، رسالة ماجستير غير منشورة ، كلية التربية ، جامعة أم القرى .

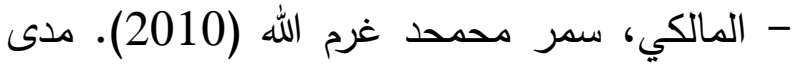
إدراك طالبات الدراسات العليا بجامعة أم القرى لهر لهري

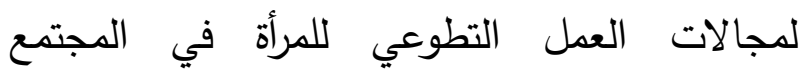


Motivations and Benefits of Student Volunteering: Comparing Regular, Occasional, and NonVolunteers in Five Countries. Canadian Journal of Nonprofit and Social Economy Research, 1(1) 65-81.

- Daoud, Nihaya (2010) :What do women gain from volunteering? The experience of lay Atab and Jewish women volunteers in the Women for Women s Health programmer in Israel, Peer Reviewed Journal, Health \& Social Care in the Community. 18.

- Esmond , Judy(2001): The untapped potential of Australian University students ,Australian Journal on Volunteering ,5(2) , 309.

- Grönlund, H. (2012). Volunteerism as a mirror of individuals and society: reflections from young adults in Finland (Unpublished Academic Dissertation), University of Helsinki, Finland.

- Ohsaka , H. (2008): The life course of middle -aged and women volunteers and their ways of overcoming negative events, The Japanese Journal of Social Psychology .24,Aug.

- Rashad,M.D.(2018). Voluntary work among university students, Journal of Educational and Psychological Researches, 15(56), 409-437.

- Schlitz, M. Vieten, C. \& Miller, M. (2010), Worldview Transformation and the Development of Social Consciousness, Journal of Consciousness Studies, 17(7-8), 18 $-36$.

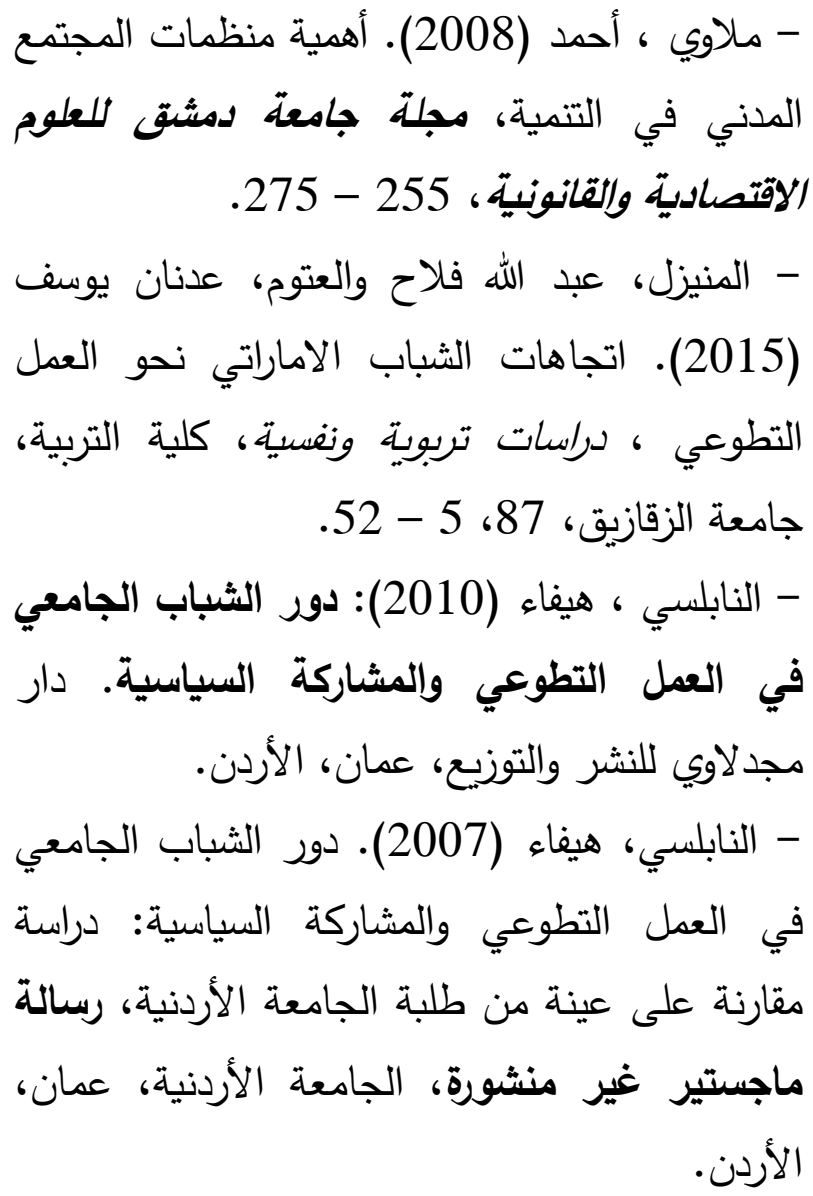

- وليم، لامبرت وولاس إ. لامبرت (2013). علم النفس الاجتماعي. ترجمة سلوى الملا، ط5،

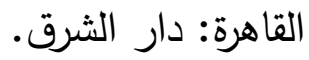

- ياسين أيمن (2002). الثباب والعمل الاجتماعي التطوعي. دركز التميز للمنظمات غير الحكومية ،القاهرة .

- يعقوب، أحمد والسلمي، عبد الله ( 2005). إدارة العمل التطوعي. الرياض: مكتبة الملك فهد

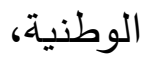

- Cnaan, R. A., Smith, K. A., Holmes, K., Haski-Leventhal, D., \& Handy, F. (2010). 


\title{
The culture of volunteer work for female university students in the light of some demographic variables
}

\author{
Sumaya A. Ahmed \\ Associate Professor of Educational Psychology \\ Faculty of Social Sciences, University of Jeddah, Jeddah, Saudi Arabia \\ Minia University - College of Education - Department of Educational Psychology \\ E-mail: somiali42@yahoo.com
}

\begin{abstract}
. the he aim of the current research is to reveal the nature of the correlative relationships between awareness of the concept of volunteerism, the attitude towards it, its motives and participation in it which constitute the culture of volunteer work according to the perception developed by the researcher -.. And the difference in the degree of responses of the sample members to the studied variables, in addition to the differences in the research variables according to the variables of the academic year and academic specialization. In order to achieve these goals, the descriptive approach was used in both its relational and comparative parts, and measures of awareness of the concept of volunteer work, the trend towards volunteer work, the motives of volunteer work, and the measure of participation in volunteer work were prepared by the researcher after confirming their psychometric characteristics on a sample of (150) female students. In the preparatory and fourth years of the University of Jeddah in the academic year $1441 \mathrm{AH} / 2020 \mathrm{AD}$. By treating the data statistically, it was concluded that there are positive statistically significant correlations between the research variables. The degree of awareness of the concept of volunteer work ranged from medium to high. The level of both the trend towards volunteering and its motivation is very high. The degree of responses of the members of the research sample to participating in volunteer work ranged between very low and high. In addition to the absence of statistically significant differences in the research variables according to the academic year (preparatory / fourth) and specialization (literary / scientific). Based on the research results, a number of recommendations were made
\end{abstract}

Key words: Culture of volunteer work - Attitude towards volunteer work - Motives of volunteer work Participation in volunteer work. 